\title{
Characterisation of Non-Saccharomyces Yeasts Using Different Methodologies and Evaluation of their Compatibility with Malolac- tic Fermentation
}

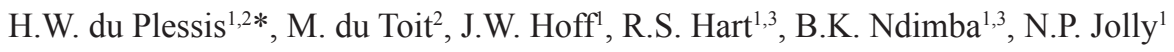

(1) ARC Infruitec-Nietvoorbij (The Fruit, Vine and Wine Institute of the Agricultural Research Council), Private Bag X5026, Stellenbosch 7599, South Africa

(2) Institute for Wine Biotechnology \& Department of Oenology and Viticulture, Stellenbosch University, Private Bag X1, Matieland 7602, South Africa

(3) National Agricultural Proteomics Research \& Services Unit (NAPRSU), University of the Western Cape, Private Bag X17, Bellville, 7535, South Africa

Submitted for publication: July 2016

Accepted for publication: October 2016

Key words: Bio-typing, karyotyping, enzyme activity, malic acid degradation, fermentation kinetics, synthetic wine

\begin{abstract}
Although Saccharomyces cerevisiae is the yeast species predominantly used for alcoholic fermentation, non-Saccharomyces yeast species are also important because they produce secondary metabolites that can contribute to the final flavour and taste of wines. In this study, 37 strains representing seven nonSaccharomyces species were characterised and evaluated for potential use in wine production, as well as for their effects on malolactic fermentation (MLF). Contour-clamped homogeneous electric field (CHEF) gel electrophoresis and matrix-assisted laser desorption ionisation using a time-of-flight mass spectrometer (MALDI-TOF MS) were used to verify species identity and to determine intra-species variation. Extracellular enzyme production, malic acid degradation and the fermentation kinetics of the yeasts were also investigated. CHEF karyotyping and MALDI-TOF MS were useful for identifying and typing Hanseniaspora uvarum, Lachancea thermotolerans, Candida zemplinina (synonym: Starmerella bacillaris) and Torulaspora delbrueckii strains. Only $H$. uvarum and Metschnikowia pulcherrima strains were found to have $\beta$-glucosidase activity. M. pulcherrima strains also had protease activity. Most of the strains showed limited malic acid degradation, and only Schizosaccharomyces pombe and the C. zemplinina strains showed mentionable degradation. In synthetic wine fermentations, $C$. stellata, $C$. zemplinina, $H$. uvarum, $M$. pulcherrima and $S c$. pombe strains were shown to be slow to medium fermenters, whereas L. thermotolerans and T. delbrueckii strains were found to be medium to strong fermenters. The effect of the yeasts on MLF varied, but inhibition was strain dependent.
\end{abstract}

\section{INTRODUCTION}

Yeasts play a key role in wine production. They are present on the grapes and winery equipment, or are added as starter cultures, and are responsible for alcoholic fermentation by which the grape must is transformed into wine. These yeasts can arbitrarily be divided into two categories: Saccharomyces and non-Saccharomyces (wild yeasts). Saccharomyces cerevisiae may be present at very low numbers on the grape skins, but are normally found in greater numbers on the winery equipment (Fleet et al., 2002; Ribéreau-Gayon et al., 2006). Non-Saccharomyces yeast genera frequently found on grapes and in must include Hanseniaspora (Kloeckera), Candida, Metschnikowia, Brettanomyces, Kluyveromyces,
Schizosaccharomyces, Torulaspora, Rhodotorula, Zygosaccharomyces, Cryptococcus and the black pigmented yeastlike fungi, Aureobasidium pullulans (Fleet et al., 2002; Jolly et al., 2003a; Ribéreau-Gayon et al., 2006; Romano et al., 2006; Jolly et al., 2014; Alessandria et al., 2015; Capozzi et al., 2015). In the initial phase of spontaneous fermentations, strains from the genera Kloeckera and Candida usually dominate (Ribéreau-Gayon et al., 2006; Romano et al., 2006). As the ethanol levels increase, the more ethanoltolerant Saccharomyces yeast strains dominate.

Malolactic fermentation (MLF) is a secondary but important fermentation process conducted by lactic acid

*Corresponding author: E-mail address: dplessishe@arc.agric.za

Acknowledgements: The authors thank the ARC, Winetech and the National Research Foundation of South Africa (THRIP programme, grant numbers UID 71526 and 86086) for funding. The opinions, findings and conclusions expressed in this paper are those of the authors. The National Research Foundation accepts no liability in this regard. Mses V. van Breda, S. Ohlson, P. Adonis, G. Mohammed and D. September are thanked for technical assistance 
bacteria (LAB), usually Oenococcus oeni (Bauer \& Dicks, 2004; Lerm et al., 2010). Malolactic fermentation is not a true "fermentation", but rather an enzymatic reaction in which malic acid is decarboxylated to lactic acid and $\mathrm{CO}_{2}$. This process is often desired in the production of red wines, and in certain white and sparkling wine styles (Wibowo et al., 1985; Bartowsky et al., 2015), because it increases wine microbiological stability and enhances aroma and flavour (Davis et al., 1985; Bartowsky et al., 2002, Lerm et al., 2010; Sumby et al., 2014).

In the last decades, research has focused on the role that non-Saccharomyces yeasts play in wine production. The use of controlled mixed cultures of selected non-Saccharomyces and Saccharomyces strains can have advantages over fermentations inoculated with pure cultures of $S$. cerevisiae. These mixed fermentations lead to the production of wines with more desirable characteristics, and starter cultures containing non-Saccharomyces yeasts, namely Torulaspora delbrueckii, Lachancea thermotolerans, Pichia kluyveri and Metschnikowia pulcherrima, are available commercially (Jolly et al., 2014). Specific compounds produced by nonSaccharomyces yeasts that can affect wine aroma and flavour include acetaldehyde, acetic acid, esters, glycerol, higher alcohols, terpenoids and other by-products (Romano et al., 1997; 2003; Jolly et al., 2006; Comitini et al., 2011; Jolly et al., 2014). Non-Saccharomyces yeasts also possess various degrees of $\beta$-glucosidase activity, which plays a role in releasing volatile compounds from non-volatile precursors (Rosi et al., 1994; Hernández-Orte et al., 2008). Extracellular proteolytic and pectinolytic enzymes of non-Saccharomyces yeasts might also be beneficial by improving wine processing through the facilitation of juice extraction and clarification, wine filtration and colour extraction (Van Rensburg \& Pretorius, 2000; Strauss, 2003; Reid, 2012). Strains of Candida stellata, C. zemplinina (synonym: Starmerella bacillaris), Hanseniaspora uvarum, M. pulcherrima and $P$. anomala have been found to produce a variety of extracellular enzymes (Charoenchai et al., 1997; Strauss, 2003; Mostert, 2013).

Considering the great diversity and potential applications of different non-Saccharomyces yeast strains within the same species, it is important to devise simple and reliable molecular typing techniques to discriminate at the subspecies level. The application of karyotyping electrophoresis techniques, such as contour-clamped homogeneous electric field (CHEF) gel electrophoresis, has been useful to differentiate nonSaccharomyces yeasts at species and strain level (EsteveZarzoso et al., 2001; Sipiczki, 2004; Alcoba-Flórez et al., 2007; Van Breda et al., 2013). Its high discriminatory power and repeatability also justify why this technique is often considered favourably in comparison with other typing methods. Matrix-assisted laser desorption ionisation, using a time-of-flight mass spectrometer (MALDI-TOF MS), is a 'soft' or non-destructive method that can be used for the identification of yeasts and bacteria at the genus and species level (Van Veen et al., 2010). Studies using MALDI-TOF MS to identify yeasts have focused more on clinical Candida strains (Marklein et al., 2009) than on wine-associated yeasts (Moothoo-Padayachie et al., 2013; Kántor \& Kačániová, 2015).
The interactions between different non-Saccharomyces yeasts (naturally present and inoculated) and LAB, as well as their impact on MLF, have received little attention. The resulting impact on wine aroma/flavour is also uncertain. With the increasing number of non-Saccharomyces yeasts available commercially, the need for a better understanding of the interactions between the wine yeast, $S$. cerevisiae, the non-Saccharomyces yeasts and LAB is critical. Therefore, the aims of this study were to characterise strains from seven non-Saccharomyces species by means of CHEF karyotyping, MALDI-TOF bio-typing, enzyme activity and malic acid degradation in order to investigate their use in wine production and to evaluate their compatibility with MLF.

\section{MATERIALS AND METHODS \\ Characterisation \\ Isolation and cultivation of micro-organisms}

The yeast strains used in this study are listed in Table 1 and included one $C$. stellata, seven $C$. zemplinina (synonym: St. bacillaris), $11 \mathrm{H}$. uvarum (anamorph: Kloeckera apiculata), two L. thermotolerans (previously Kluyveromyces thermotolerans), seven M. pulcherrima (anamorph: Candida pulcherrima), one Schizosaccharomyces pombe, eight Torulaspora delbrueckii (anamorph: Candida colliculosa) and six $S$. cerevisiae strains. Strain L. thermotolerans Viniflora ${ }^{\circledR}$ Rhythm ${ }^{\mathrm{TM}}$ (Chr. Hansen, Denmark) and T. delbrueckii strains Viniflora ${ }^{\circledR}$ Harmony ${ }^{\mathrm{TM}}$ (Chr. Hansen), (Level $^{2} \mathrm{TD}^{\mathrm{TM}}$ (Lallemand Inc., France) and Zymaflore ${ }^{\circledR}$ Alpha TD n. Sacc. (Laffort Oenologie, France), were isolated from commercial active dried yeast blends (Van Breda et al., 2013 and this study) and included as reference strains. All the yeasts were stored under cryo-preservation at $-80^{\circ} \mathrm{C}$. When required, the yeasts were grown on yeast peptone dextrose agar (YPDA, Merck, South Africa) at $28^{\circ} \mathrm{C}$ for 48 hours, or until sufficient growth was observed. Single colonies were then selected and transferred to $10 \mathrm{~mL}$ YPD broth and grown for 24 hours at $28^{\circ} \mathrm{C}$ before inoculation. Oenococcus oeni (Viniflora ${ }^{\circledR}$ oenos, Chr. Hansen) was used to induce MLF according to the supplier's instructions.

\section{Electrophoretic karyotyping}

Contour-clamped homogeneous electric field (CHEF) gel electrophoresis was used to investigate the strain diversity of the non-Saccharomyces yeasts, and the intact chromosomal DNA was prepared using the embedded agarose technique described by Hoff (2012). A CHEF DRIII electrophoretic apparatus (Bio-Rad Laboratories, Inc., Richmond, USA) and the method described by Hoff (2012) were used with the following changes to the running conditions: 34-hour programme, initial pulse was $30 \mathrm{~s}$ and final pulse was $215 \mathrm{~s}$ at an angle of 120 degrees at a constant 6 volt; 72-hour programme, initial and final pulse of $1800 \mathrm{~s}$ at an angle of 106 degrees at a constant 2.5 volt. Saccharomyces cerevisiae reference strain CBS 432 was used as the standard reference strain for all CHEF gels and was loaded on the outer lanes of each gel. Agarose gels at a concentration of $1.2 \%$ and $0.8 \%$ were used to separate yeasts run on the 34 and 72 hour programmes respectively. 
TABLE 1

Yeasts used in this study

\begin{tabular}{|c|c|c|c|}
\hline Species name & $\begin{array}{l}\text { Strain } \\
\text { code }\end{array}$ & Strain, origin and source information & References* \\
\hline \multirow{6}{*}{$\begin{array}{l}\text { Saccharomyces } \\
\text { cerevisiae }\end{array}$} & S1 & $\begin{array}{l}\text { N 96, commercial yeast from Anchor Wine Yeast, South } \\
\text { Africa }\end{array}$ & Hoff, 2012 \\
\hline & $\mathrm{S} 2$ & $\begin{array}{l}\text { VIN 13, commercial yeast from Anchor Wine Yeast, South } \\
\text { Africa }\end{array}$ & $\begin{array}{l}\text { Jolly et al., 2003b; 2003c; } \\
\text { Hoff, 2012; Van Breda et al., } \\
\text { 2013; Minnaar et al., } 2015\end{array}$ \\
\hline & $\mathrm{S} 3$ & $\begin{array}{l}\text { NT 112, commercial yeast from Anchor Wine Yeast, South } \\
\text { Africa }\end{array}$ & Hoff, 2012 \\
\hline & S4 & $\begin{array}{l}\text { NT 202, commercial yeast from Anchor Wine Yeast, South } \\
\text { Africa }\end{array}$ & Hoff, 2012; Scholtz, 2013 \\
\hline & S5 & $\begin{array}{l}\text { VIN 7, commercial yeast from Anchor Wine Yeast, South } \\
\text { Africa }\end{array}$ & Hoff, 2012 \\
\hline & S6 & $\begin{array}{l}\text { CBS 432, from Centraalbureau voor Schimmelcultures } \\
\text { (CBS), Netherlands }\end{array}$ & \\
\hline Candida stellata & Cs & CBS $157^{\mathrm{T}}$, from CBS, Netherlands & $\begin{array}{l}\text { Sipiczki, 2004; Csoma \& } \\
\text { Sipiczki, } 2008\end{array}$ \\
\hline \multirow{7}{*}{$\begin{array}{l}\text { Candida zemplinina } \\
\text { (synonym: } \\
\text { Starmerella } \\
\text { bacillaris) }\end{array}$} & $\mathrm{C} 1$ & CBS 9494, type strain from CBS, Netherlands & $\begin{array}{l}\text { Sipiczki, 2004; Csoma \& } \\
\text { Sipiczki, 2008, Magyar et al., } \\
2014\end{array}$ \\
\hline & $\mathrm{C} 2$ & VEN 2097, from the University of California, Davis & Bokulich et al., 2012 \\
\hline & $\mathrm{C} 3$ & $770^{* *}$, from the ARC Infruitec-Nietvoorbij, South Africa & Jolly et al., 2003b** \\
\hline & $\mathrm{C} 4$ & 788 , from the ARC Infruitec-Nietvoorbij, South Africa & This study \\
\hline & $\mathrm{C} 5$ & 841, from the ARC Infruitec-Nietvoorbij, South Africa & This study \\
\hline & C6 & 971, from the ARC Infruitec-Nietvoorbij, South Africa & This study \\
\hline & $\mathrm{C} 7$ & C2-19, from the ARC Infruitec-Nietvoorbij, South Africa & This study \\
\hline \multirow{11}{*}{$\begin{array}{l}\text { Hanseniaspora } \\
\text { uvarum } \\
\text { (anamorph: } \\
\text { Kloeckera apiculata) }\end{array}$} & $\mathrm{H} 1$ & 752, from the ARC Infruitec-Nietvoorbij, South Africa & Jolly et al., 2003b \\
\hline & $\mathrm{H} 2$ & 791, from the ARC Infruitec-Nietvoorbij, South Africa & This study \\
\hline & H3 & 802, from the ARC Infruitec-Nietvoorbij, South Africa & This study \\
\hline & $\mathrm{H} 4$ & 897, from the ARC Infruitec-Nietvoorbij, South Africa & This study \\
\hline & H5 & 899, from the ARC Infruitec-Nietvoorbij, South Africa & This study \\
\hline & H6 & 913, from the ARC Infruitec-Nietvoorbij, South Africa & This study \\
\hline & $\mathrm{H} 7$ & 918, from the ARC Infruitec-Nietvoorbij, South Africa & This study \\
\hline & $\mathrm{H} 8$ & 932, from the ARC Infruitec-Nietvoorbij, South Africa & This study \\
\hline & H9 & 934, from the ARC Infruitec-Nietvoorbij, South Africa & This study \\
\hline & $\mathrm{H} 10$ & 961, from the ARC Infruitec-Nietvoorbij, South Africa & This study \\
\hline & H11 & 980, from the ARC Infruitec-Nietvoorbij, South Africa & This study \\
\hline \multirow{2}{*}{$\begin{array}{l}\text { Lachancea } \\
\text { thermotolerans } \\
\text { (previously } \\
\text { Kluyveromyces } \\
\text { thermotolerans) }\end{array}$} & L1 & $\begin{array}{l}\text { Viniflora }{ }^{\circledR} \text { Rhythm }{ }^{\mathrm{TM}} \text {, commercial yeast from Chr. Hansen, } \\
\text { Denmark }\end{array}$ & This study \\
\hline & L2 & 548, from the ARC Infruitec-Nietvoorbij, South Africa & This study \\
\hline \multirow{7}{*}{$\begin{array}{l}\text { Metschnikowia } \\
\text { pulcherrima } \\
\text { (anamorph: Candida } \\
\text { pulcherrima) }\end{array}$} & M1 & 825 , from the ARC Infruitec-Nietvoorbij, South Africa & Jolly et al., 2003b; 2003c \\
\hline & M2 & $\mathrm{C} 1 / 15$, from the ARC Infruitec-Nietvoorbij, South Africa & Jolly et al., 2003c \\
\hline & M3 & 780, from the ARC Infruitec-Nietvoorbij, South Africa & This study \\
\hline & M4 & 870 , from the ARC Infruitec-Nietvoorbij, South Africa & This study \\
\hline & M5 & 950, from the ARC Infruitec-Nietvoorbij, South Africa & This study \\
\hline & M6 & O2/16, from the ARC Infruitec-Nietvoorbij, South Africa & This study \\
\hline & M7 & O2/17, from the ARC Infruitec-Nietvoorbij, South Africa & This study \\
\hline $\begin{array}{l}\text { Schizosaccharomyces } \\
\text { pombe }\end{array}$ & $\mathrm{Sp}$ & CBS 5557, CBS, Netherlands & This study \\
\hline
\end{tabular}




\begin{tabular}{|c|c|c|c|}
\hline Species name & $\begin{array}{l}\text { Strain } \\
\text { code }\end{array}$ & Strain, origin and source information & References* \\
\hline \multirow{8}{*}{$\begin{array}{l}\text { Torulaspora } \\
\text { delbrueckii } \\
\text { (anamorph: Candida } \\
\text { colliculosa) }\end{array}$} & T1 & CBS $1146^{\mathrm{T}}, \mathrm{CBS}$, Netherlands & Van Breda et al., 2013 \\
\hline & $\mathrm{T} 2$ & CBS 4663, CBS, Netherlands & Van Breda et al., 2013 \\
\hline & T3 & Level $^{2} \mathrm{TD}^{\mathrm{TM}}$, commercial strain from Lallemand Inc, France & This study \\
\hline & $\mathrm{T} 4$ & $\begin{array}{l}\text { Zymaflore }{ }^{\circledR} \text { Alpha }{ }^{\mathrm{TD} \text { n. Sacc. }} \text {, commercial strain from Laffort, } \\
\text { France }\end{array}$ & This study \\
\hline & $\mathrm{T} 5$ & $\begin{array}{l}\text { Viniflora }{ }^{\circledR} \text { Harmony }{ }^{\mathrm{TM}} \text {, commercial yeast from } \mathrm{Chr} \text {. } \\
\text { Hansen, Denmark }\end{array}$ & Van Breda et al., 2013 \\
\hline & T6 & M2/1, from the ARC Infruitec-Nietvoorbij, South Africa & $\begin{array}{l}\text { Jolly et al., 2003b; Van Breda } \\
\text { et al., } 2013\end{array}$ \\
\hline & $\mathrm{T} 7$ & 654, from the ARC Infruitec-Nietvoorbij, South Africa & $\begin{array}{l}\text { Van Breda et al., 2013; } \\
\text { Minnaar et al., } 2015\end{array}$ \\
\hline & $\mathrm{T} 8$ & 301, from the ARC Infruitec-Nietvoorbij, South Africa & Van Breda et al., 2013 \\
\hline
\end{tabular}

*Publications in which strains have been investigated.

**Strain 770 was classified as Candida stellata in this paper.

Chromosomal banding patterns were visualised on a Bio-Rad image analyser following staining with $0.01 \%$ (v/v) ethidium bromide (Bio-Rad Laboratories, Inc.). Normalisation of gels and comparison of banding patterns were done using FPQuest ${ }^{\mathrm{TM}}$ software (Bio-Rad Laboratories, Inc.) and the normalised electrophoretic patterns were grouped. Similarities (s) were obtained using the Dice coefficient, before cluster analysis was performed by the unweighted pair group method with arithmetic mean (UPGMA).

\section{MALDI-TOF bio-typing}

Single colonies of each yeast strain were selected for identification and bio-typing by MALDI-TOF MS. One micro-litre of wine yeast protein extract was spotted onto a MTP 384 polished steel target plate as described by Moothoo-Padayachie et al. (2013) and Deak et al. (2015). Thereafter, the spotted target plate was inserted into a Bruker UltrafleXtreme MALDI-TOF MS (Bruker Daltonics, Bremen, Germany) apparatus. Generation of yeast protein mass spectra using MALDI-TOF/TOF MS was conducted according to the standard National Agricultural Proteomics Research \& Services Unit method (obtainable from the National Agricultural Proteomics Research \& Services Unit (NAPRSU), University of the Western Cape, South Africa). Mass spectra for all strains were acquired in triplicate. The spectrum acquired for each sample was compared to the Bruker reference database, which contains 4110 microorganisms (NAPRSU, May 2015).

\section{Enzyme screening and malic acid degradation}

Polygalacturonase/pectinase activity was determined as described by McKay (1988), $\beta$-glucosidase activity was determined through the screening method of Strauss et al. (2001) and acid protease activity was determined following the method of Charoenchai et al. (1997). The ability of yeasts to degrade malic acid was determined using the plate assay method described by Mocke (2005). The medium used for malic acid degradation was also modified slightly by excluding the agar and bromocresol green to determine malic acid degradation in a liquid medium. Aliquots of $10 \mathrm{~mL}$ of medium were dispensed into 42 test tubes and autoclaved. After this, single colonies of the yeast strains were inoculated into the test tubes containing the MLF broth and kept at an ambient temperature of $22^{\circ} \mathrm{C}$ for up to 40 days. Malic acid concentration was measured by enzymatic analysis (Arena 20XT enzyme robot, Institute for Wine Biotechnology, Stellenbosch University).

\section{Evaluation of yeasts \\ Fermentation trial}

Laboratory-scale alcoholic fermentation trials were conducted in a chemically defined grape juice as described by Costello et al. (2003). Yeasts were grown in $10 \mathrm{~mL}$ of YPD broth at $30^{\circ} \mathrm{C}$ prior to inoculation. Pure cultures of the different yeast strains were inoculated into sterilised $375 \mathrm{~mL}$ glass bottles containing $250 \mathrm{~mL}$ of filter-sterilised synthetic grape juice and fermented to dryness. Each yeast strain had three biological repeats. After the alcoholic fermentation (AF), the resultant synthetic wine of each yeast treatment was pooled, aseptically filtered $(0.22 \mu \mathrm{m})$ and used for the MLF trial. Fifty millilitres of the synthetic wine were aliquoted into sterilised $250 \mathrm{~mL}$ bottles before inoculating with LAB. Two treatments were applied, viz. (1) addition of $O$. oeni only and (2) addition of nutrients as described by Costello et al. (2003) prior to the addition of $O$. oeni (Viniflora ${ }^{\circledR}$ oenos). Alcoholic and malolactic fermentations were conducted at $\pm 22^{\circ} \mathrm{C}$.

\section{Chemical analyses}

The Ripper method as described by Iland et al. (2000) was used to determine free and total $\mathrm{SO}_{2}$. The sugar concentration, $\mathrm{pH}$, malic acid, total acidity (TA), alcohol and volatile acidity (VA) of the synthetic wines were determined using an OenoFoss ${ }^{\mathrm{TM}}$ Fourier transform infrared (FTIR) spectrometer (FOSS Analytical A/S, Denmark).

\section{RESULTS AND DISCUSSION}

The role of non-Saccharomyces yeasts in wine production is not as well researched as the role of $S$. cerevisiae (Jolly 
et al., 2014). Although T. delbrueckii, L. thermotolerans and $M$. pulcherrima are receiving much more attention due to the availability of commercial products, a variety of other nonSaccharomyces yeast species have been investigated (Jolly et al., 2003b; Comitini et al., 2011; Jolly et al., 2014; Padilla et al., 2016). In this investigation, 37 non-Saccharomyces strains representing seven different non-Saccharomyces species, viz. H. uvarum, L. thermotolerans, M. pulcherrima, Sc. pombe, C. zemplinina, C. stellata and T. delbrueckii, were characterised by CHEF karyotyping, MALDI-TOF bio-typing, enzyme assays and malic acid degradation. The aforementioned non-Saccharomyces yeasts were compared to five commercial $S$. cerevisiae strains (N 96, NT 112, NT 202, VIN 7 and VIN 13), and their interactions with one $O$. oeni strain were investigated in synthetic grape juice. As the species-level identities of the yeasts used in this study were already known, CHEF karyotyping and MALDI-TOF biotyping were used to study strain diversity within the different species (Figs 1, 2 and 3).

\section{$\%$ Similarity}

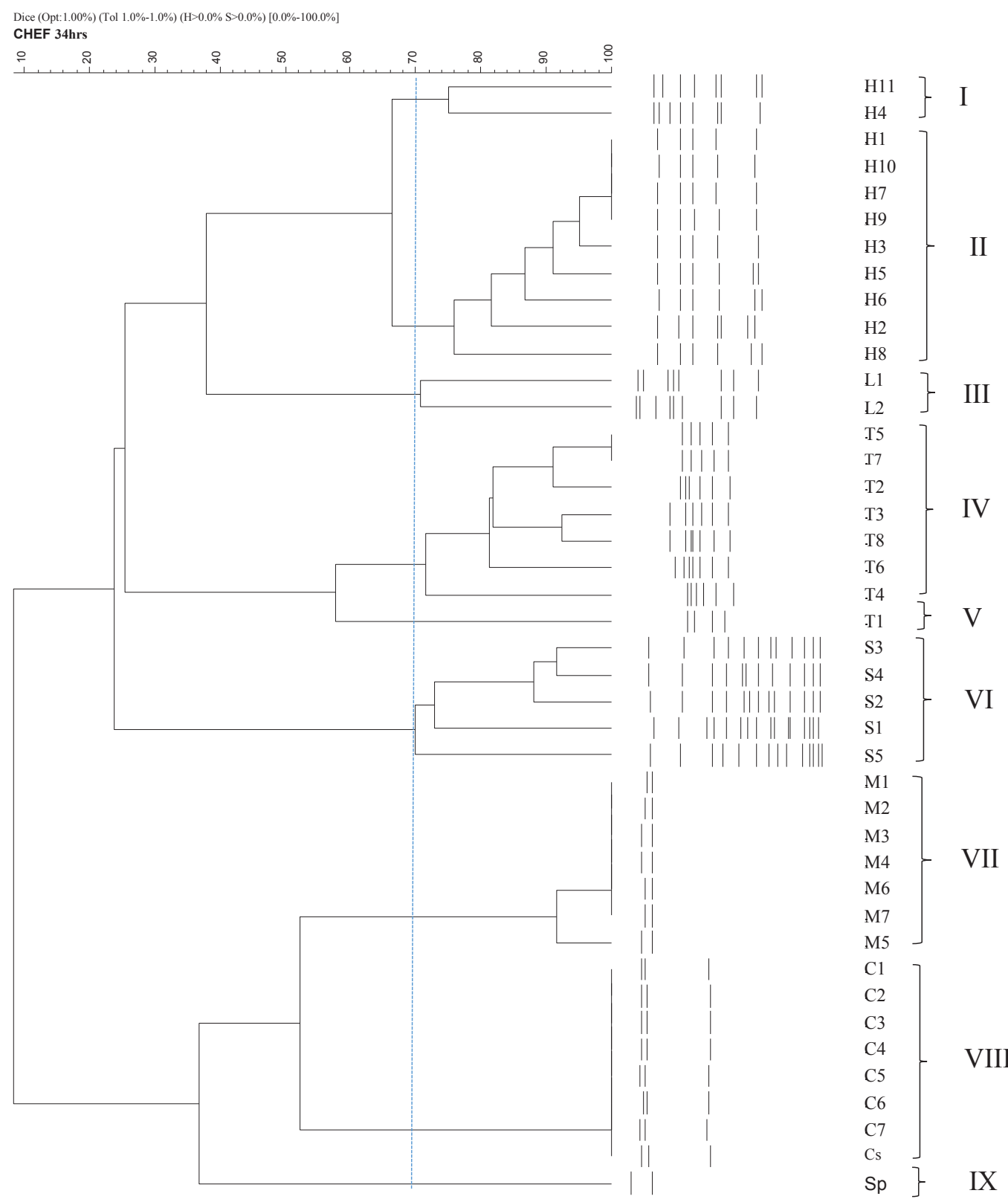

FIGURE 1

Dendrogram showing the clustering of yeast strains obtained by numerical analysis of CHEF karyotypes using a 34-hour programme. Cluster analysis was performed using the unweighted pair group method with arithmetic mean (UPGMA). Cluster I and II: Hanseniaspora uvarum strains; III: Lachancea thermotolerans strains; IV and V: Torulaspora delbrueckii strains; VI: Saccharomyces cerevisiae strains; VII: Metschnikowia pulcherrima; VIII: Candida zemplinina (Starmerella bacillaris) and Candida stellata strains; and IX: Schizosaccharomyces pombe. 


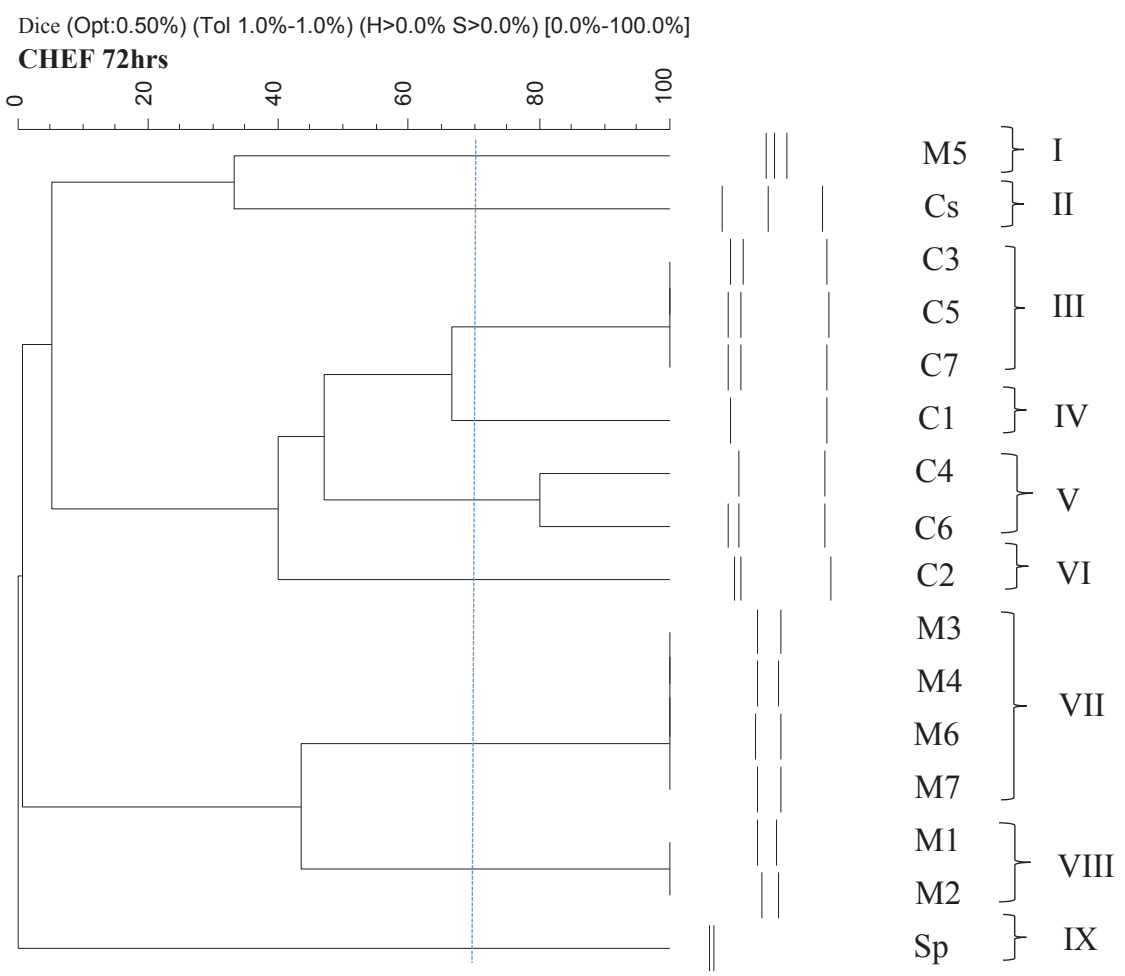

FIGURE 2

Dendrogram showing the clustering of yeast strains obtained by numerical analysis of CHEF karyotypes using the 72-hour programme. Cluster analysis was performed using the unweighted pair group method with arithmetic mean (UPGMA). Cluster I: Metschnikowia pulcherrima; Cluster II: Candida stellata; Clusters III, IV, V and VI: C. zemplinina; Clusters VII and VIII: M. pulcherrima; and Cluster IX: Schizosaccharomyces pombe.

\section{Electrophoretic karyotyping}

The results of the CHEF karyotyping of the 34- and 72-hour programmes are shown in Figs 1 and 2 respectively. The Dice coefficient was used to group the yeasts based on the similarities of the electrophoretic banding patterns obtained. The 34-hour programme enabled the various yeasts to be separated to species and, in some cases, also to strain level (Fig. 1). The species could be separated into nine distinct clusters at a similarity $(s)$ limit of $70 \%$.

Cluster I was delineated at $s=75 \%$ and comprised two H. uvarum strains, H4 and H11, which were different from the other nine H. uvarum strains. Cluster II was delineated at $s=76 \%$ and included the remaining $H$. uvarum strains, viz. $\mathrm{H} 1, \mathrm{H} 2, \mathrm{H} 3, \mathrm{H} 5, \mathrm{H} 6, \mathrm{H} 7, \mathrm{H} 8, \mathrm{H} 9$ and H10. Within this cluster, strains H1, H7, H9 and H10 had an almost identical karyotype and were delineated at $s=100 \%$. Strains H9 and H10 were isolated from grapes from the same location and may well be the same strain, but strains $\mathrm{H} 1$ and $\mathrm{H} 7$ were isolated from different areas within the Western Cape. This indicates that $H$. uvarum strains might not be as heterogeneous as $S$. cerevisiae strains. Cluster III comprised the two L. thermotolerans strains, L1 (Vinflora ${ }^{\circledR}$ Rhythm ${ }^{\mathrm{TM}}$ ) and L2, delineated at $s=70 \%$. There were clear differences between the karyotypes of these two strains. Seven T. delbrueckii strains, viz. T2 (CBS 4663), T3 (Level $2^{\mathrm{Td}}$ ), T4 (Zymaflore ${ }^{\circledR}$ Alpha $^{\text {TD n. Sacc. }), ~ T 5 ~(V i n i f l o r a ~}{ }^{\circledR}$ Harmony $^{\mathrm{TM}}$ ), T6, T7 and T8, formed cluster IV at $s=70 \%$. T. delbrueckii-type strain, T1 (CBS 1146), clustered alone in cluster V at $s=58 \%$.

Cluster VI comprised the five $S$. cerevisiae strains at $s=$ $70 \%$ and these strains showed a high level of heterogeneity. These results confirmed reports by Hoff(2012) and MoothooPadaychie et al. (2013) on the heterogeneity of S. cerevisiae wine yeast strains. The M. pulcherrima strains formed cluster VII at $s=92 \%$. All the strains had a similarity of $100 \%$, except strain M5. The only difference for the M. pulcherrima karyotypes was the spacing between bands within the banding patterns. Cluster VIII was delineated at $s=100 \%$, comprised all the $C$. zemplinina strains, including the type strain (CBS 9494), and also contained the C. stellata-type strain, Cs (CBS 157). These two species are closely related and were only reclassified as two different species when Sipiczki $(2003$; 2004) revealed the differences between them. More recently, Duarte et al. (2012) recommended the reinstatement of Starmerella bacillaris comb. nov. with the name $C$. zemplinina as obligate synonym, which has not been widely accepted (Magyar et al., 2014). As in the case of the $M$. pulcherrima cluster, the patterns of the $C$. zemplinina strains are very similar, with small spacing differences. Sc. pombe grouped on its own to form cluster IX at $s=38 \%$, but showed some similarity with the M. pulcherrima strains, which also had only two bands.

The 34-hour CHEF programme was very useful for 


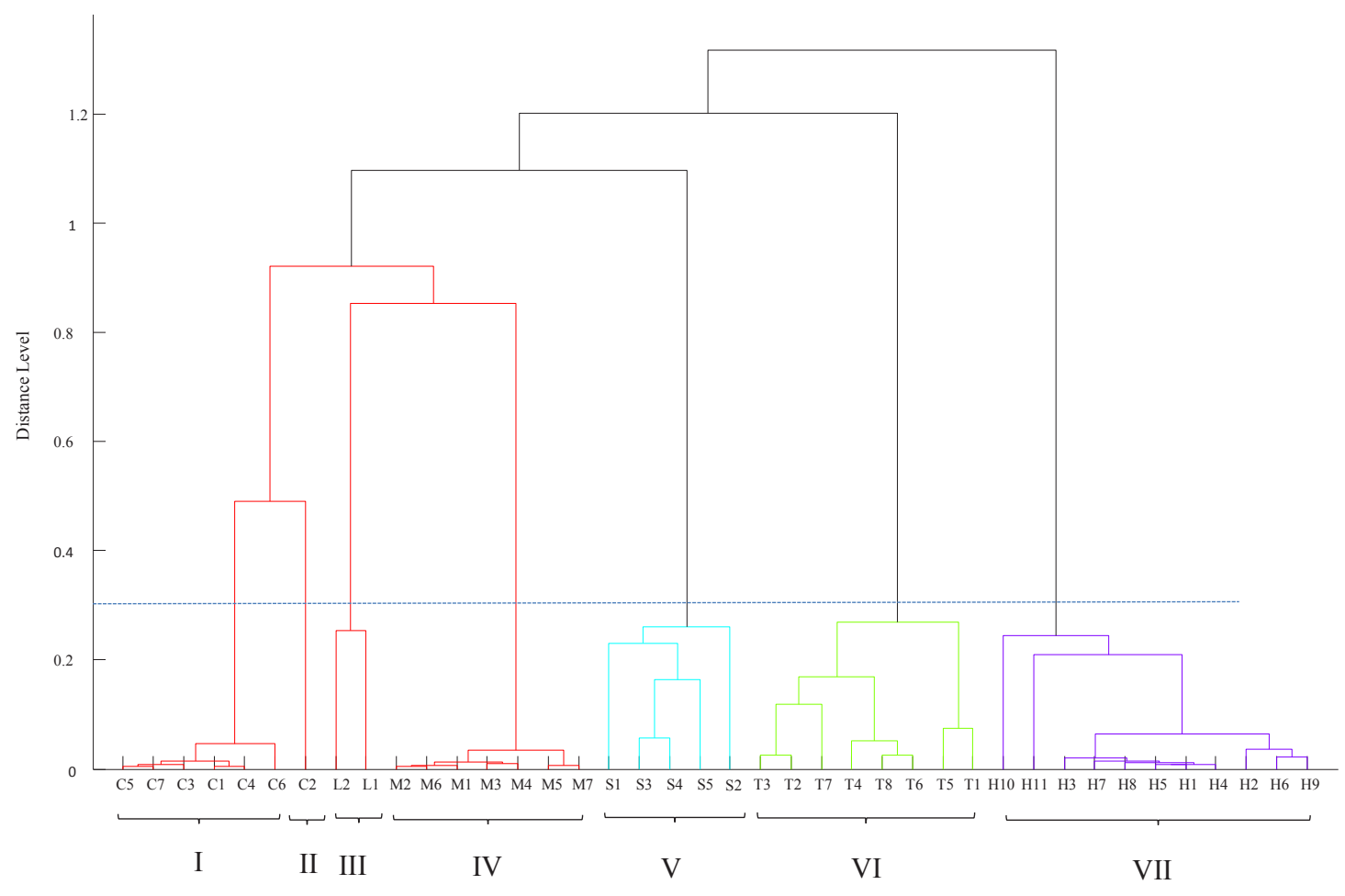

FIGURE 3

Dendrogram created from the mass spectral profiles of yeast strains using MALDI Biotyper software. Cluster I and II: Candida zemplinina (Starmerella bacillaris) strains; III: Lachancea thermotolerans strains; IV: Metschnikowia pulcherrima; V: Saccharomyces cerevisiae strains; VI: Torulaspora delbrueckii strains; and VII: Hanseniaspora uvarum strains.

the typing of the $S$. cerevisiae strains and strains within the H. uvarum, L. thermotolerans and T. delbrueckii clusters. However, it was not nearly as effective for typing M. pulcherrima and C. zemplinina strains. This confirms reports by Van Breda (2012) about the usefulness of CHEF for the typing of T. delbrueckii strains. However, the 34hour programme could not be used to distinguish between $M$. pulcherrima and C. zemplinina at a strain level, therefore an extended 72-hour CHEF programme was investigated.

The clustering analysis of the 72-hour programme is shown in Fig. 2. Nine clusters could be discerned at $s=70 \%$. Cluster I was delineated at $s=33 \%$ and comprised only M. pulcherrima strain M5. The banding pattern of this strain was different to the other M. pulcherrima strains, and this was also evident in the grouping of the strains using the 34-hour programme (Fig. 1). Cluster II comprised the C. stellatatype strain (Fig. 2). Cluster III contained three C. zemplinina strains, C3, C5 and C7, at $s=100 \%$. These C. zemplinina strains had identical karyotypes, indicating that these isolates are possibly the same strain. Strains C3 and C7 were isolated from grapes on the same farm and may well be the same strain. Despite being isolated from a different area, it is possible that strain $\mathrm{C} 5$ might be the same strain as $\mathrm{C} 3$ and C7. Cluster IV was delineated at $s=66 \%$ and comprised only strain C1 (CBS 9494). Cluster V was delineated at $s=80 \%$ and comprised strains $\mathrm{C} 4$ and C6. Cluster VI was delineated at $s=40 \%$ and comprised one strain, C2. More differences were observed among the $C$. zemplinina strains with the 72-hour programme than with the 34-hour programme. The M. pulcherrima strains formed clusters VII (M3, M4, M6 and M7) and VIII (M1 and M2) at $s=44 \%$. Strains M4, M6 and M7 were isolated from the same location and could possibly be the same strain. This would explain the similarity between these strains. However, strain M3 was isolated from a different area within the Western Cape (South Africa). As was observed with the 34-hour programme, the karyotypes of the different strains were very similar. This indicates a high level of conserved genetic material within the small group of strains investigated. Cluster IX contained the one Sc. pombe strain, which had a completely different banding pattern from the other species, and this was also confirmed by a low similarity value.

More differences were observed between strains from the $C$. zemplinina and M. pulcherrima clusters with the 72hour programme than the 34-hour programme. Candida zemplinina strains showed a higher level of heterogeneity than the M. pulcherrima strains with the 72-hour programme. This indicates that the CHEF programmes used in this study were not adequate for the typing of M. ulcherrima strains and that more optimisation is required. Differences were observed between the karyotypes of $C$. emplinina and $C$. stellata strains using the 72-hour programme, which is in agreement with the findings of Sipiczki (2004) and Csoma and Sipiczki (2008), who performed electrophoretic karyotyping over 99 and 96 hrs respectively. Similar results were obtained in this study, but using a shorter running time $(72 \mathrm{~h})$. This study confirmed that CHEF is a reliable technique for the identification of non-Saccharomyces yeast to the species and strain level. However, more optimisation and refinement are required for the typing of $M$. pulcherrima strains. 


\section{MALDI-TOF bio-typing}

The results of the MALDI-TOF MS analyses (Fig. 3) show that the non-Saccharomyces and $S$. cerevisiae yeasts formed distinct groups. The identity of H. uvarum, M. pulcherrima, $S$. cerevisiae, Sc. pombe and $T$. delbrueckii could all be verified to species level using the MALDI Biotyper database. As L. hermotolerans, C. zemplinina and C. stellata were not in the MALDI Biotyper database, it could not be used to identify these strains. However, the MALDI-TOF MS profiles could be used to differentiate between strains within a species. The six non-Saccharomyces species could be grouped into seven clusters following cluster analysis of the mass spectra obtained at a phylogenetic distance level of 0.3 , indicated by the dotted line in Fig. 3. Cluster I and II comprised the C. zemplinina strains, with strain $\mathrm{C} 2$ positioning on its own. The strains in cluster I showed a high level of similarity and grouped closely together. The composition of the C. zemplinina groupings differed from the groupings obtained using the 72-hour CHEF programme. Cluster III consisted of the two L. thermotolerans strains, which clearly differed from each other. Cluster IV consisted of all the M. pulcherrima strains, which also showed a high level of similarity and grouped closely together. Cluster V comprised the $S$. cerevisiae strains and appear to be a heterogeneous cluster. The $T$. delbrueckii strains grouped together in cluster VI and three sub-groups can be differentiated within this cluster. These strains show a high degree of variation. Cluster VII comprised the H. uvarum strains, which showed a high level of similarity, although four sub-groups could be differentiated. The H. uvarum strains $\mathrm{H} 10$ and $\mathrm{H} 11$ differed from the other strains and formed separate sub-groups. Strains H2, H6 and H9 also formed a separate sub-group. Strains H1, H3, H4, H5, H7 and H8 all grouped together and had a level of similarity. The sub-groups differed from the groupings obtained using CHEF karyotyping, indicating that isolates that were considered to be identical might be different strains.

The MALDI-TOF MS results were easier and faster to obtain than the CHEF karyotyping results. In both cases, software was needed for normalisation and clustering analyses. Both CHEF and MALDI-TOF MS were useful for species identification and could clearly type strains from S. cerevisiae, L. thermotolerans, T. delbrueckii and H. uvarum, with the MALDI-TOF MS profiles showing slightly more variation. Neither technique was effective for the typing of $C$. zemplinina and $M$. pulcherrima strains, with MALDI-TOF MS revealing slightly more differences among the $M$. pulcherrima strains, and the 72-hour CHEF programme being more effective for the typing of C. zemplinina strains. For the typing of species with high genetic similarity, i.e. M. pulcherrima strains, alternative methods, such as amplified fragment length polymorphism (Spadaro et al., 2008) or tandem repeat-tRNA PCR (Barquet et al., 2012), could be considered. This study showed that MALDI-TOF MS can be used for the identification and typing of non-Saccharomyces yeasts and confirms the findings of Kántor and Kačániová (2015) about the usefulness of MALDI-TOF MS to differentiate between wine yeast species. However, MALDI-TOF MS was not as effective for typing C. zemplinina and M. pulcherrima strains.

\section{Enzyme production}

The ability of the eight non-Saccharomyces yeast species to produce acid protease, polygalacturonase/pectinase and $\beta$-glucosidase enzymes and to degrade malic acid is shown in Table 2. The $S$. erevisiae strains used in this study did not produce any extracellular enzymes. Charoenchai et al. (1997) reported some $\beta$-glucosidase activity in some S. cerevisiae strains, but Mostert (2013) found that the $S$. cerevisiae strain they tested did not have $\beta$-glucosidase or acid protease activity, but produced pectinase enzymes. The C. stellata strain was only positive for protease production and this is in agreement with the findings of Strauss (2003), who also showed that some $C$. stellata strains showed pectinolytic activity. Protease activity could be beneficial during fermentation by liberating assimilable nutrient sources, such as amino acids and peptides (Englezos et al., 2015). All the $C$. zemplinina strains tested negative for all three enzyme activities. Di Maio et al. (2012) and Englezos et al. (2015) reported medium to low $\beta$-glucosidase activity for C. zemplinina strains. Englezos et al. (2015) reported protease activity in 48 of 63 C. zemplinina strains studied, but none of the strains had pectinase activity.

The H. uvarum strains tested positive for $\beta$-glucosidase and negative for the other two enzyme activities. This confirmed the findings of Rodríguez et al. (2004) and Hernández-Orte et al. (2008), namely that $H$. uvarum strains have $\beta$-glucosidase activity. Strauss (2003) and Mostert (2013) also reported on H. uvarum strains that had protease and pectinase activity.

The two L. thermotolerans strains tested negative for all three enzyme activities. This is in contrast to Comitini et al. (2011) and Mostert (2013), who reported $\beta$-glucosidase activity in two L. thermotolerans strains. As in the case with the other species, enzyme activity appears to be strain dependent. All the $M$. pulcherrima strains were positive for protease and $\beta$-glucosidase activity, which is in agreement with the literature (Strauss, 2003; Mostert, 2013). The one Sc. pombe strain showed protease activity. Visintin et al. (2016) also reported on a $S c$. pombe strain that had protease activity and a different $S c$. pombe strain that produced pectinase. The results of this study confirmed the conclusion of Ganga and Martínez (2004) that enzyme production is not characteristic of a particular genus or species, but depends on the yeast strain analysed.

\section{Malic acid degradation}

The $S$. cerevisiae strains showed no malic acid degradation on the plate assay, but showed low activity in the broth, with S5 (VIN 7) utilising about $24 \%$ of the malic acid (Table 2). The low malic acid utilisation by $S$. cerevisiae is well documented (Gao \& Fleet, 1995; Volschenk et al., 2003; Ribéreau-Gayon et al., 2006). The ability of the nonSaccharomyces strains to degrade malic acid varied greatly and there also were clear differences between the results of the plate and broth assays. The results indicate that the plate assay for malic acid utilisation is not very reliable, as it gave a lot of negative results as well as false positives. The C. stellata strain produced a positive reaction for malic acid utilisation on the plate assay, but could only utilise $9 \%$ of the malic acid in the broth assay. All the $C$. zemplinina strains 
TABLE 2

Screening of Saccharomyces and non-Saccharomyces yeasts for production of extracellular enzymes and the ability to degrade malic acid.

\begin{tabular}{|c|c|c|c|c|c|c|c|}
\hline \multirow[b]{2}{*}{ Species name } & \multirow{2}{*}{$\begin{array}{l}\text { Strain } \\
\text { code }\end{array}$} & \multicolumn{3}{|c|}{ Enzyme activities } & \multicolumn{3}{|c|}{ Malic acid degradation } \\
\hline & & Protease & Pectinase & $\beta$-Glucosidase & Plate assay & Broth & $\%$ Utilised \\
\hline \multirow{5}{*}{ Saccharomyces cerevisiae } & $\mathrm{S} 1$ & - & - & - & - & - & 13 \\
\hline & $\mathrm{S} 2$ & - & - & - & - & - & 11 \\
\hline & $\mathrm{S} 3$ & - & - & - & - & - & 11 \\
\hline & S4 & - & - & - & - & - & 12 \\
\hline & S5 & - & - & - & - & - & 24 \\
\hline Candida stellata & $\mathrm{Cs}$ & + & - & - & + & - & 9 \\
\hline \multirow{7}{*}{ Candida zemplinina } & $\mathrm{C} 1$ & - & - & - & + & + & 54 \\
\hline & $\mathrm{C} 2$ & - & - & - & + & + & 34 \\
\hline & $\mathrm{C} 3$ & - & - & - & + & + & 37 \\
\hline & $\mathrm{C} 4$ & - & - & - & + & + & 33 \\
\hline & C5 & - & - & - & + & + & 34 \\
\hline & C6 & - & - & - & + & + & 51 \\
\hline & $\mathrm{C} 7$ & - & - & - & + & + & 47 \\
\hline \multirow{11}{*}{ Hanseniaspora uvarum } & H1 & - & - & + & + & + & 10 \\
\hline & $\mathrm{H} 2$ & - & - & + & + & + & 30 \\
\hline & $\mathrm{H} 3$ & - & - & + & + & + & 9 \\
\hline & H4 & - & - & + & + & + & 11 \\
\hline & H5 & - & - & + & + & + & 12 \\
\hline & H6 & - & - & + & + & + & 14 \\
\hline & $\mathrm{H} 7$ & - & - & + & + & - & 8 \\
\hline & H8 & - & - & + & + & - & 7 \\
\hline & H9 & - & - & + & + & - & 9 \\
\hline & H10 & - & - & + & + & - & 10 \\
\hline & H11 & - & - & + & + & - & 7 \\
\hline \multirow{2}{*}{ Lachancea thermotolerans } & L1 & - & - & - & + & + & 20 \\
\hline & $\mathrm{L} 2$ & - & - & - & + & - & 10 \\
\hline \multirow{7}{*}{ Metschnikowia pulcherrima } & M1 & + & - & + & - & - & 15 \\
\hline & M2 & + & - & + & - & + & 23 \\
\hline & M3 & + & - & + & + & + & 22 \\
\hline & M4 & + & - & + & - & + & 24 \\
\hline & M5 & + & - & + & - & + & 28 \\
\hline & M6 & + & - & + & - & + & 26 \\
\hline & M7 & + & - & + & - & + & 20 \\
\hline Schizosaccharomyces pombe & $\mathrm{Sp}$ & + & - & - & + & + & 78 \\
\hline \multirow{8}{*}{ Torulaspora delbrueckii } & $\mathrm{T} 1$ & - & - & - & - & - & 14 \\
\hline & $\mathrm{T} 2$ & - & - & - & - & - & 11 \\
\hline & $\mathrm{T} 3$ & - & - & - & - & + & 19 \\
\hline & $\mathrm{T} 4$ & - & - & - & - & + & 31 \\
\hline & $\mathrm{T} 5$ & - & - & - & - & + & 18 \\
\hline & T6 & - & - & - & - & - & 8 \\
\hline & $\mathrm{T} 7$ & - & - & - & - & + & 18 \\
\hline & $\mathrm{T} 8$ & - & - & - & - & - & 11 \\
\hline
\end{tabular}


gave positive results for malic acid utilisation on the plate assay and in the broth, with malic acid utilisation ranging from 33 to $54 \%$.

All the $H$. uvarum strains also gave positive reactions for malic acid utilisation on the plate assay, but only strain $\mathrm{H} 2$ showed real malic acid utilisation (30\%) in the broth. The other H. uvarum strains utilised only between $7 \%$ and $14 \%$ of the malic acid in the broth. T. delbrueckii strains gave negative results for malic acid utilisation on the plate assay, but showed variable malic acid utilisation (11\% to $31 \%$ ) in the broth, with strain T4 (Zymaflore ${ }^{\circledR}$ Alpha TD n. Sacc.) showing the most activity (31\%). The above results are in agreement with reports of low malic acid utilisation for C. stellata, T. delbrueckii and H. uvarum (Gao \& Fleet, 1995; Saayman \& Viljoen-Bloom, 2006). The L. thermotolerans strains were also able to degrade malic acid on the plate assay, but were not as efficient in the broth, with strain L1 (Vinflora ${ }^{\circledR}$ Rhythm ${ }^{\mathrm{TM}}$ ) managing to utilise $20 \%$ of the malic acid. Only strain M3 gave a positive reaction on the plate assay, but all the M. pulcherrima strains showed some malic acid utilisation ( $15 \%$ to $28 \%$ ).

As expected, the $S c$. pombe strain gave a positive reaction on the plate assay and utilised $78 \%$ of the malic acid in the broth. Strains of $S c$. pombe can degrade high concentrations of L-malate, but only if glucose or another assimilable carbon source is present (Baranowski \& Radler, 1984; Rodriquez \& Thornton, 1989, Benito et al., 2013; 2014).

\section{Evaluation of yeasts}

Fermentation trial

The ability of the non-Saccharomyces yeast to ferment synthetic juice and the progress of alcoholic fermentation are shown in Figs 4 to 8 . The fermentations were monitored regularly for 40 days, but the final wine chemical analyses were carried out after 180 days, when the wines produced with the slow-fermenting yeasts were found to be dry (glucose/fructose $<4 \mathrm{~g} / \mathrm{L}$ ). Candida zemplinina strains showed variable fermentation abilities, with strains C1 (CBS 9494) and C2 (VEN 2097) standing out as the strongest fermenters, although still not comparable to the $S$. cerevisiae strains (Fig. 4). According to Csoma and Sipiczki (2008), C. zemplinina strains can be found throughout white and red wine fermentations and usually have sustained presence until the end of alcoholic fermentation. This study showed that some of the $C$. zemplinina strains have enough fermentation potential to be used in mixed culture fermentations.

The H. uvarum strains were slow to moderate fermenters, with strain H11 being the strongest fermenter (Fig. 5). The low fermentation activity of $H$. uvarum is in agreement with Ciani and Maccarelli (1998). The M. pulcherrima strains were also slow fermenters and most were still fermenting after 40 days, with the exception being strain M6 (Fig. 6). This concurs with reports from other studies (Jolly et al., 2003c; Mostert \& Divol, 2014). The T. delbrueckii strains were strong fermenters and had fermentation rates that were comparable to the $S$. cerevisiae reference strains (Fig. 7). This concurs with the reports of Van Breda et al. (2013) and Renault et al. (2015). The two L. thermotolerans strains were also strong fermenters and comparable to the $S$. cerevisiae strains (Fig. 8). These results confirmed the findings of Comitini et al. (2011) and Mostert and Divol (2014). The fact that both $T$. delbrueckii and $L$. thermotolerans are such strong fermenters is probably one of the reasons why strains from these species were selected for use as commercial starters in mixed culture fermentations with $S$. cerevisiae (Jolly et al., 2014). The Sc. pombe strain is a moderate

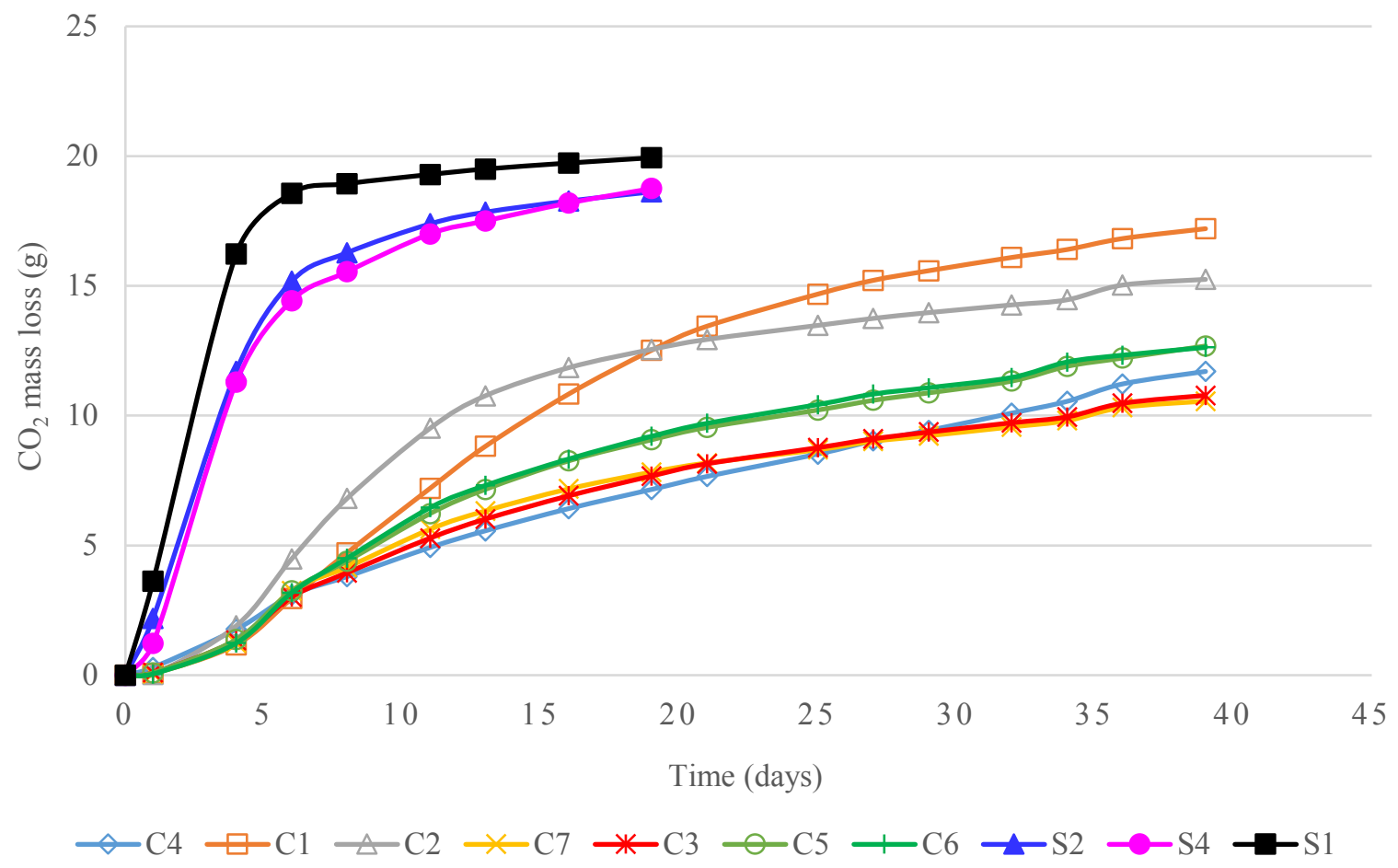

FIGURE 4

Fermentation kinetics of pure cultures of Saccharomyces cerevisiae and Candida zemplinina strains in synthetic grape juice. 
fermenter and fermentation activity may vary between strains (Benito et al., 2012; 2013). The C. stellata strain was a slow fermenter.

\section{Chemical analyses}

The results of the chemical analyses of synthetic wines produced with the different yeast species are listed in Table 3. The fermentations conducted by the slow-fermenting yeasts
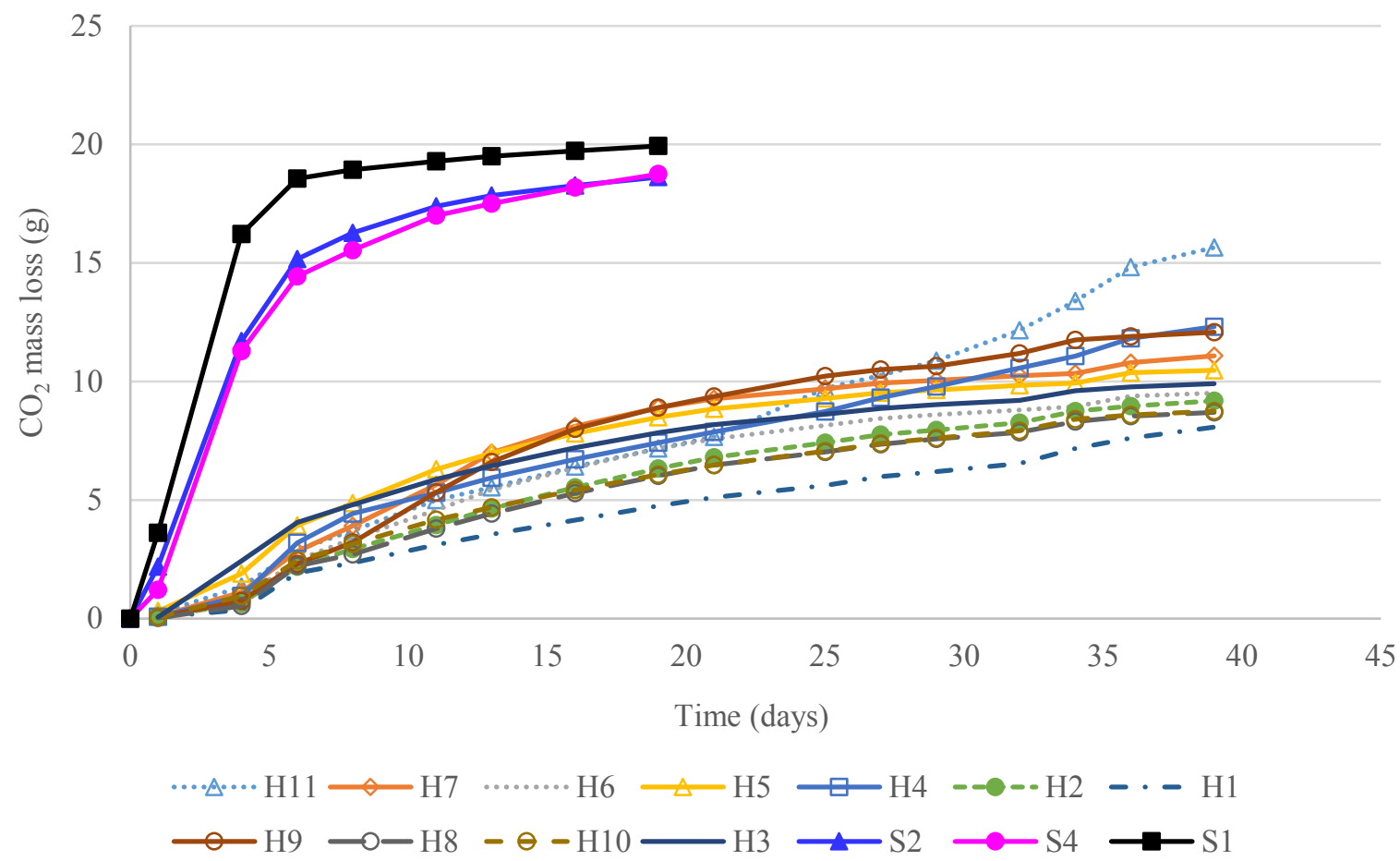

FIGURE 5

Fermentation kinetics of pure cultures of Saccharomyces cerevisiae and Hanseniaspora uvarum strains in synthetic grape juice.

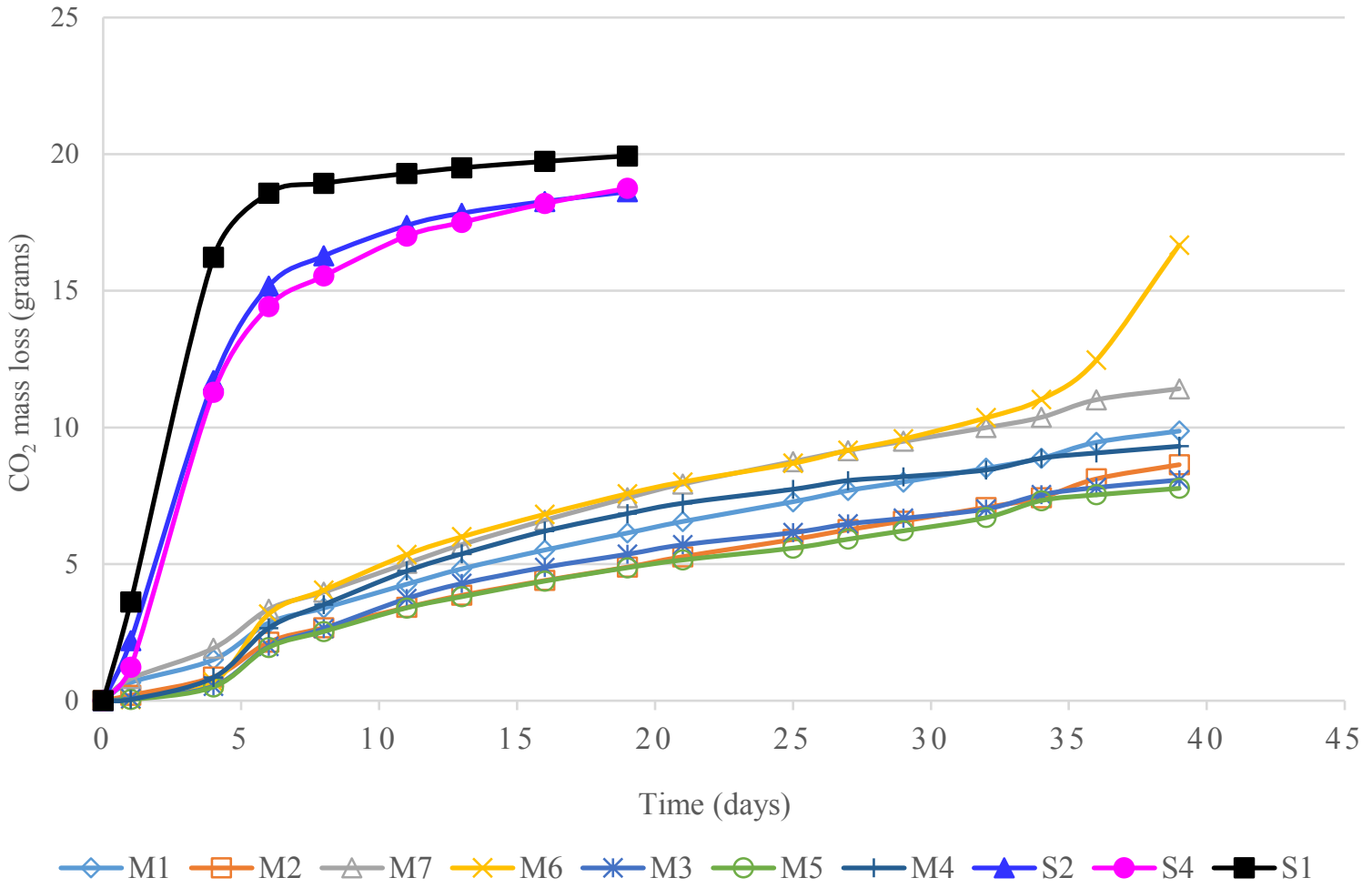

FIGURE 6

Fermentation kinetics of pure cultures of Saccharomyces cerevisiae and Metschnikowia pulcherrima strains in synthetic grape juice. 


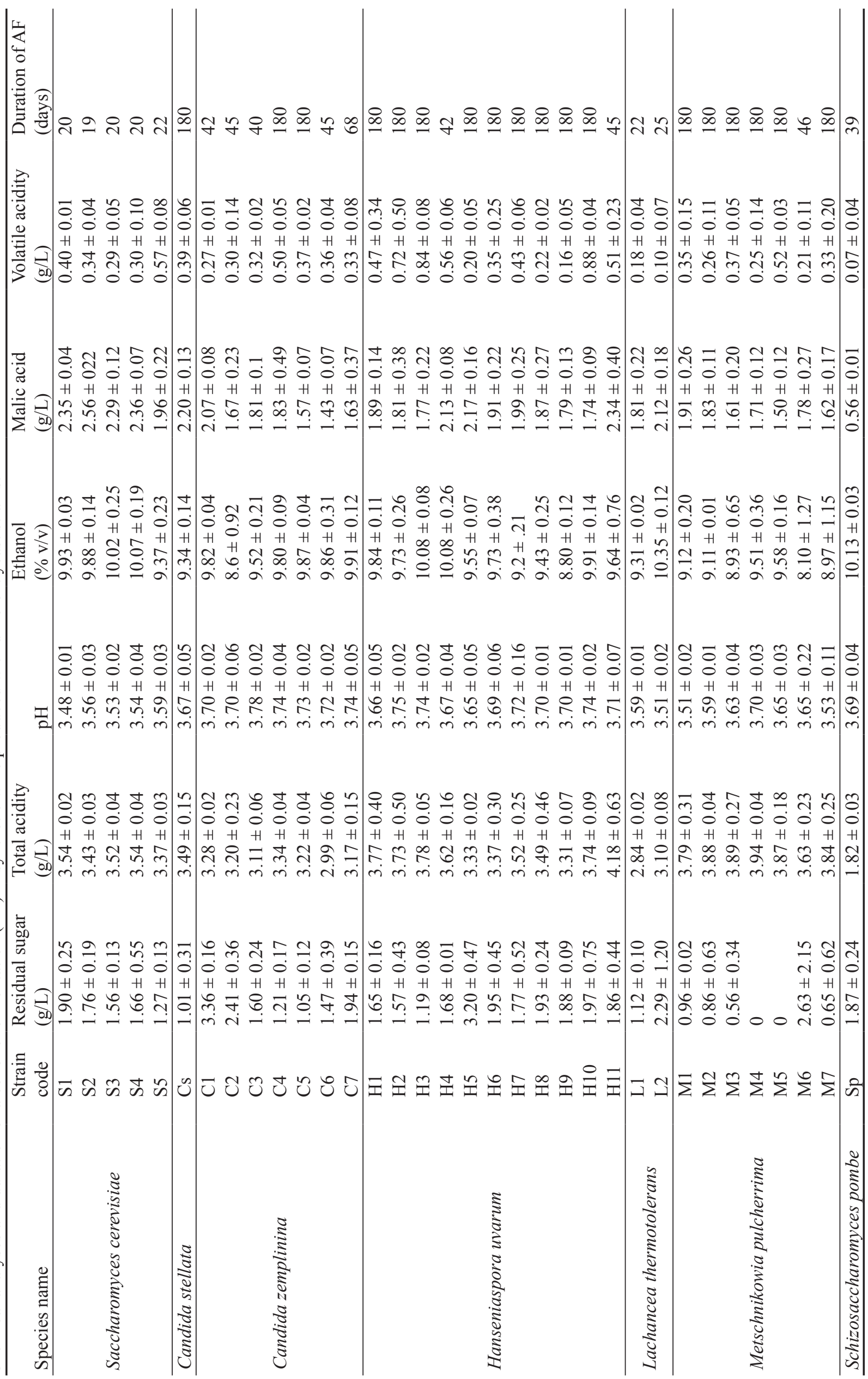




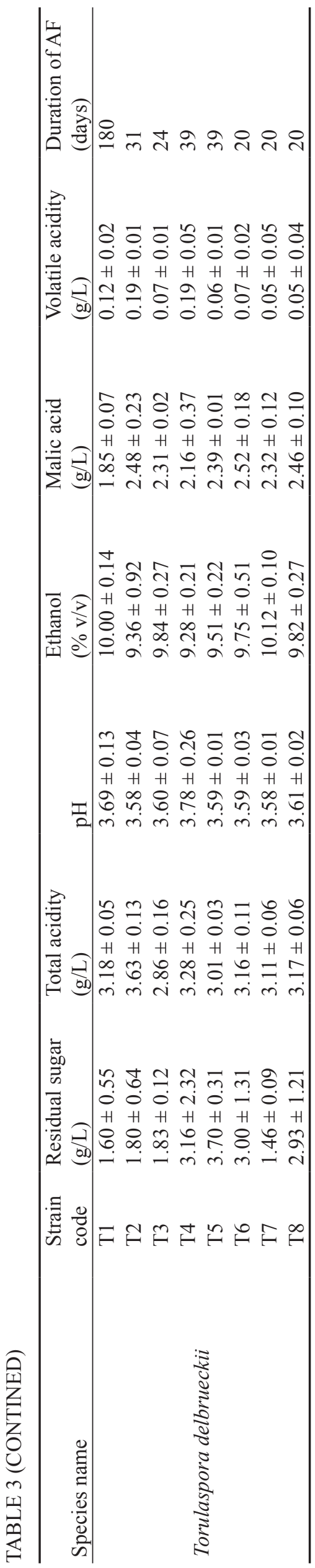

were considered to be dry (residual sugar $<4 \mathrm{~g} / \mathrm{L}$ ) after 180 days. A great degree of variation was observed among the ethanol, malic acid and volatile acidity (VA) levels of the different non-Saccharomyces yeast species and strains. Candida zemplinina strains produced low VA and were similar to the $S$. cerevisiae strains, although $C$. zemplinina strains can be low or high VA producers (Magyar \& Toth, 2011; Magyar et al., 2014; Englezos et al., 2015). Synthetic wines produced with $H$. uvarum contained high VA levels, especially wines produced with strains $\mathrm{H} 2, \mathrm{H} 3$ and $\mathrm{H} 10$. In contrast, synthetic wines produced with strains $\mathrm{H} 5, \mathrm{H} 6$, H7, H8 and H9 had low VA levels, which indicate strain variation within this species. Wines produced by other non-Saccharomyces yeasts contained lower VA levels than $H$. uvarum, which is in agreement with findings by other researchers (Ciani \& Picciotti, 1995; Rojas et al., 2003). Wines produced with the Sc. pombe strain and T. delbrueckii strains contained the lowest VA levels. This is in agreement with Moreno et al. (1991) and Renault et al. (2009), who showed that pure cultures of $T$. delbrueckii produced lower VA levels than S. cerevisiae. Benito et al. (2012; 2013 ; 2014) showed that $S c$. pombe can be moderate to high VA producers, depending on the strain. Most of the M. pulcherrima strains produced low VA levels, except for strain M5, which produced slightly higher VA levels $(0.52 \mathrm{~g} / \mathrm{L})$. M. pulcherrima is not normally associated with VA production, but rather with relatively high concentrations of esters (Bisson \& Kunkee, 1991).

The malic acid levels were lower in all synthetic wines, indicating loss due to precipitation, but also some degradation (Table 3). In most cases, synthetic wines fermented with non-Saccharomyces yeasts had lower malic acid levels than synthetic wines fermented with $S$. cerevisiae strains. Wines fermented with $S c$. pombe had a malic acid reduction of $>77 \%$, while the reduction by the other nonSaccharomyces yeast varied. These results are in agreement with those obtained for the malic acid utilisation in the malic acid broth.

\section{Malolactic fermentation}

The effect of various yeast strains on $O$. oeni growth and its ability to complete MLF prior to inoculation, with or without nutrient supplementation, is presented in Table 4. There were clear differences between the MLF treatments that were applied. In most cases, MLF proceeded quickly and without delays. However, in some cases where delays occurred, nutrient supplementation improved the progress of MLF or completely eliminated the delays. None of the yeasts produced high enough levels of $\mathrm{SO}_{2}$ to inhibit $\mathrm{LAB}$, but there were some variations between the species and among strains from the same species. Despite producing low levels of $\mathrm{SO}_{2}$, there were differences among the S. cerevisiae strains. Strains S1 and S5 had the least inhibitory effect on MLF, which was completed after seven days (Table 4). Strain S3 had an inhibitory effect on MLF, and this was evident in both treatments. In this case inhibition could be due to $\mathrm{SO}_{2}$, but the production of other inhibitory compounds is more likely. Yeasts can inhibit LAB, and therefore MLF, by depleting nutrients or by producing toxic metabolites such as ethanol, $\mathrm{SO}_{2}$, medium-chain fatty acids and proteins or peptides 


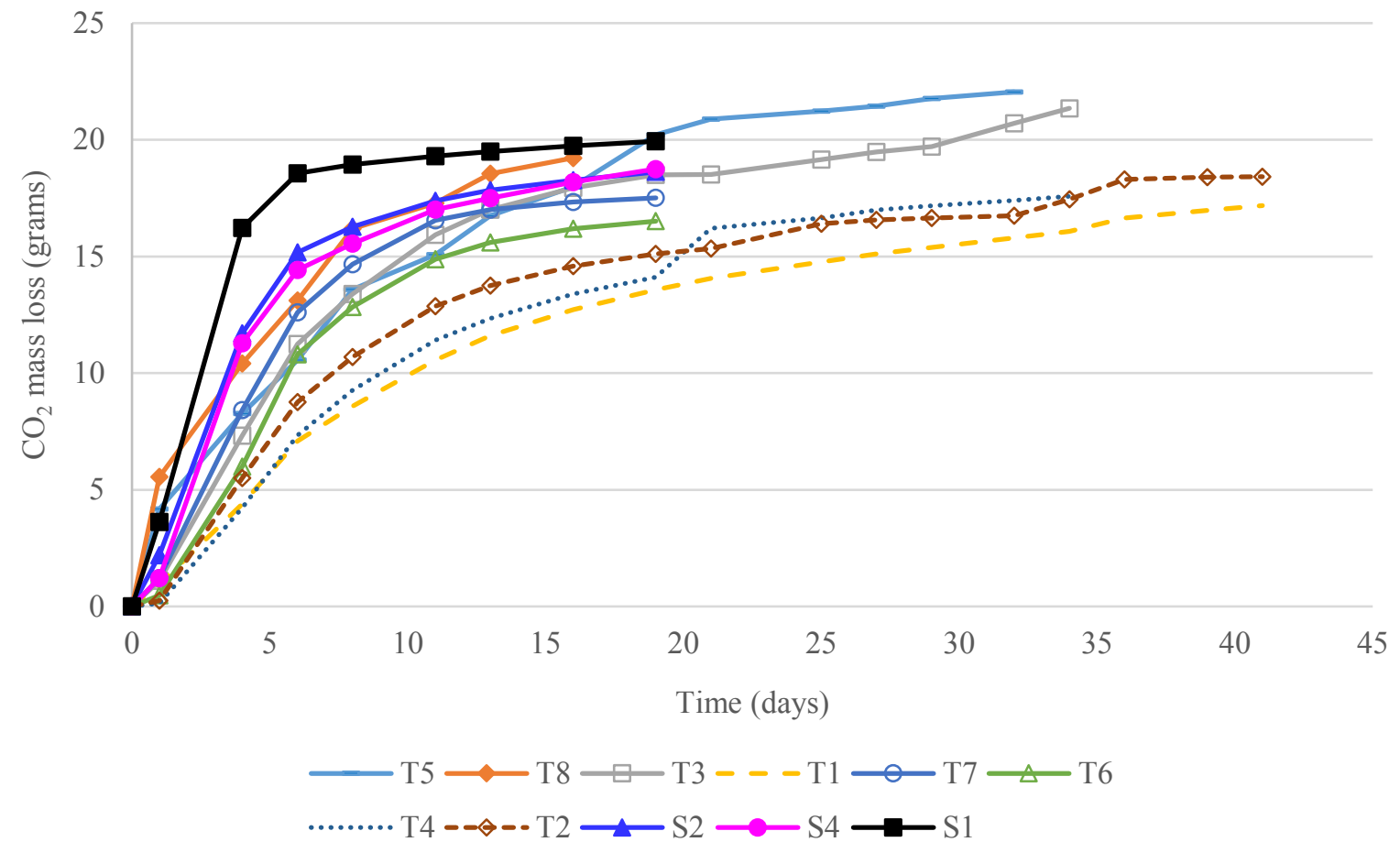

FIGURE 7

Fermentation kinetics of pure cultures of Saccharomyces cerevisiae and Torulaspora delbrueckii strains in synthetic grape juice.

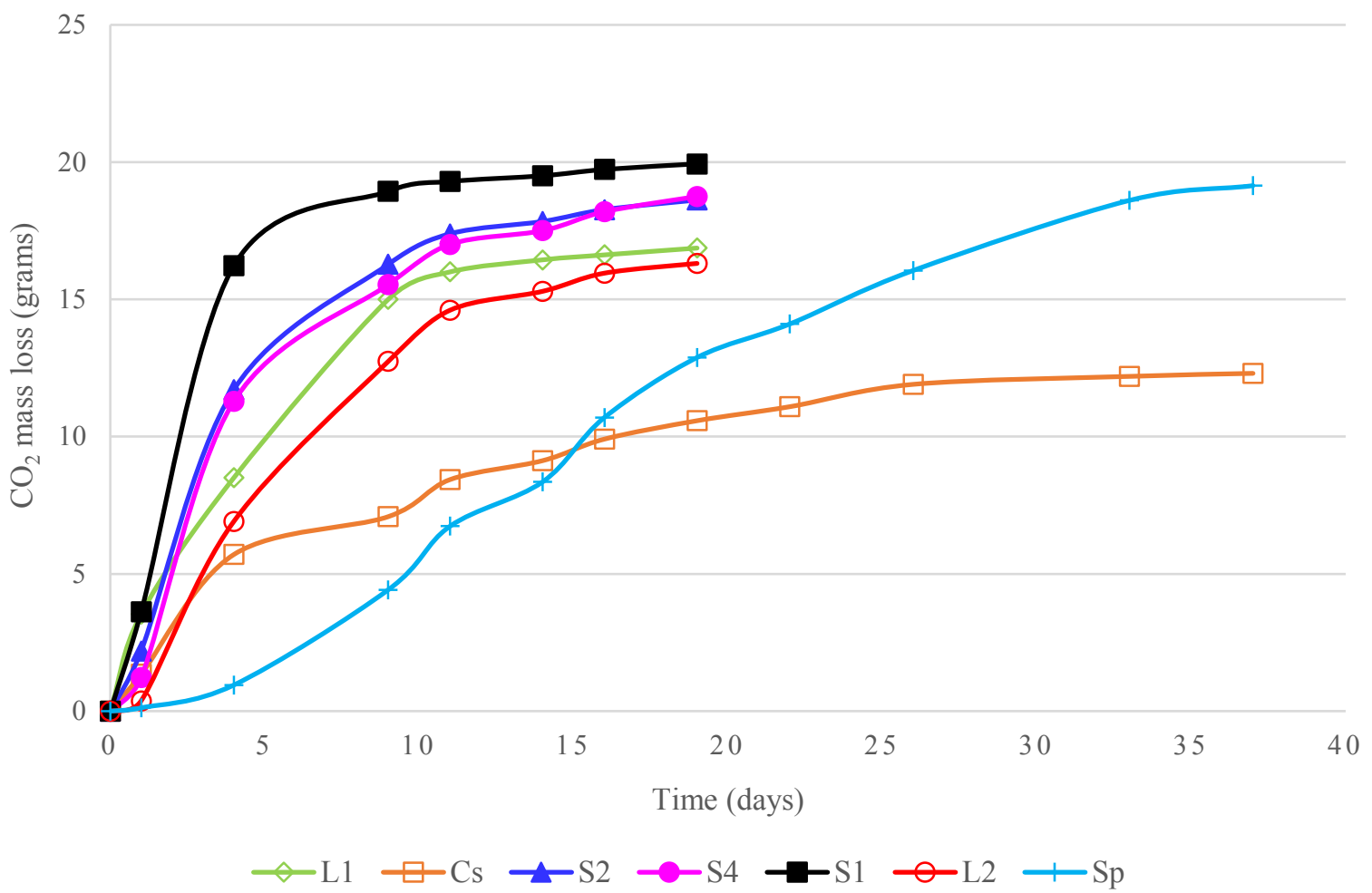

FIGURE 8

Fermentation kinetics of pure cultures of Saccharomyces cerevisiae, Lachancea thermotolerans and Schizosaccharomyces pombe strains in synthetic grape juice. 
TABLE 4

Free and total $\mathrm{SO}_{2}$ levels and duration of malolactic fermentation (MLF) in synthetic wines fermented with different yeasts.

\begin{tabular}{|c|c|c|c|c|c|}
\hline \multirow[b]{2}{*}{ Species name } & \multirow{2}{*}{$\begin{array}{l}\text { Strain } \\
\text { code }\end{array}$} & \multirow{2}{*}{$\begin{array}{l}\text { Free } \mathrm{SO}_{2} \\
(\mathrm{mg} / \mathrm{L})\end{array}$} & \multirow{2}{*}{$\begin{array}{l}\text { Total SO } \\
(\mathrm{mg} / \mathrm{L})\end{array}$} & \multicolumn{2}{|c|}{ Duration of MLF (days) } \\
\hline & & & & Treatment $1 *$ & Treatment $2 * *$ \\
\hline \multirow{5}{*}{ Saccharomyces cerevisiae } & $\mathrm{S} 1$ & 3 & 8 & 7 & 7 \\
\hline & $\mathrm{S} 2$ & 4 & 9 & 13 & 7 \\
\hline & $\mathrm{S} 3$ & 5 & 9 & 14 & 13 \\
\hline & $\mathrm{S} 4$ & 5 & 9 & 13 & 7 \\
\hline & S5 & 2 & 5 & 7 & 6 \\
\hline Candida stellata & $\mathrm{Cs}$ & 2 & 9 & 26 & 21 \\
\hline \multirow{7}{*}{ Candida zemplinina } & $\mathrm{C} 1$ & 2 & 4 & 7 & 7 \\
\hline & $\mathrm{C} 2$ & 2 & 5 & 7 & 7 \\
\hline & $\mathrm{C} 3$ & 2 & 5 & 7 & 7 \\
\hline & $\mathrm{C} 4$ & 2 & 6 & 7 & 7 \\
\hline & $\mathrm{C} 5$ & 2 & 5 & 7 & 7 \\
\hline & C6 & 2 & 5 & 7 & 7 \\
\hline & $\mathrm{C} 7$ & 2 & 6 & 20 & 7 \\
\hline \multirow{11}{*}{ Hanseniaspora uvarum } & $\mathrm{H} 1$ & 2 & 10 & 7 & 7 \\
\hline & $\mathrm{H} 2$ & 1 & 8 & 7 & 7 \\
\hline & H3 & 2 & 8 & 10 & 7 \\
\hline & $\mathrm{H} 4$ & 2 & 9 & 7 & 7 \\
\hline & H5 & 2 & 8 & 13 & 13 \\
\hline & H6 & 1 & 8 & 7 & 7 \\
\hline & $\mathrm{H} 7$ & 2 & 6 & 14 & 14 \\
\hline & H8 & 2 & 6 & 13 & 7 \\
\hline & H9 & 1 & 8 & 13 & 7 \\
\hline & $\mathrm{H} 10$ & 2 & 9 & 7 & 7 \\
\hline & $\mathrm{H} 11$ & 2 & 8 & 7 & 7 \\
\hline \multirow{2}{*}{ Lachancea thermotolerans } & L1 & 2 & 5 & 7 & 7 \\
\hline & L2 & 2 & 5 & 7 & 7 \\
\hline \multirow{7}{*}{ Metschnikowia pulcherrima } & M1 & 3 & 9 & 7 & 7 \\
\hline & M2 & 3 & 10 & 7 & 7 \\
\hline & M3 & 3 & 9 & 7 & 7 \\
\hline & M4 & 2 & 9 & 7 & 7 \\
\hline & M5 & 2 & 10 & 7 & 7 \\
\hline & M6 & 3 & 10 & 7 & 7 \\
\hline & M7 & 3 & 10 & 7 & 7 \\
\hline \multirow{8}{*}{ Torulaspora delbrueckii } & $\mathrm{T} 1$ & 2 & 10 & 7 & 7 \\
\hline & $\mathrm{T} 2$ & 2 & 8 & 14 & 14 \\
\hline & $\mathrm{T} 3$ & 2 & 4 & 13 & 7 \\
\hline & $\mathrm{T} 4$ & 2 & 5 & 7 & 7 \\
\hline & $\mathrm{T} 5$ & 2 & 5 & 7 & 7 \\
\hline & T6 & 3 & 5 & 7 & 7 \\
\hline & $\mathrm{T} 7$ & 3 & 5 & 7 & 10 \\
\hline & $\mathrm{T} 8$ & 2 & 5 & 7 & 7 \\
\hline
\end{tabular}

*Treatment 1: Sequential inoculation with commercial Oenococcus oeni strain.

**Treatment 2: Nutrient supplementation (Costello et al., 2003) prior to sequential inoculation with $O$. oeni strain. 
(Alexandre et al., 2004, Comitini et al., 2005; Nehme et al., 2008). Strains S2 and S4 also had an inhibitory effect on MLF (treatment 1), but the inhibition could be overcome by nutrient supplementation (treatment 2). The antagonistic effect of some $S$. cerevisiae on MLF has been reported, and yeast and LAB compatibility is an important factor to consider for successful MLF (Henick-Kling \& Park 1994; Costello et al., 2003).

The C. stellata strain (Cs) had an inhibitory effect on MLF (26 days) and resulted in MLF taking longer to complete (Table 4). However, delayed MLF could be partially alleviated by nutrient supplementation (treatment 2), but MLF still took 21 days. Inhibition by $C$. stellata could be partially due to nutrient depletion, but other inhibitory compounds are a more likely explanation. In general, the C. zemplinina strains did not have an inhibitory effect on MLF, except for strain C7, which took 20 days to complete MLF. The inhibitory effect of C7 was completely eliminated by nutrient supplementation.

Hanseniaspora uvarum strains $\mathrm{H} 5$ and $\mathrm{H} 7$ had a slight inhibitory effect on all MLF treatments. $\mathrm{SO}_{2}$ levels were not excessively high in these wines, indicating that some other inhibitory compound(s) was probably produced. Strains H3, H8 and H9 also had an inhibitory effect on MLF, but the inhibitory effect could be eliminated by nutrient supplementation. The L. thermotolerans and M. pulcherrima strains completed MLF quickly and were finished within seven days. No variations with regard to MLF were observed for strains within these species. The M. pulcherrima strains had the highest total $\mathrm{SO}_{2}$ levels of all the non-Saccharomyces yeast, but these did not affect the progression of MLF.

The results indicate that some of the yeast strains had a higher nutrient demand or uptake, which resulted in slower progression of MLF. The duration of MLF varied between the yeasts used, but none of the yeasts completely inhibited MLF. In the case of delayed MLF it appears to be strain dependent. $\mathrm{SO}_{2}$ was ruled out as a reason for the delays, but other toxic metabolites were not investigated. The metabolites produced by these inhibitory strains need further investigation. The results obtained in synthetic wine should be confirmed in real grape juice and wine fermentations because the interaction between the non-Saccharomyces yeast and $\mathrm{LAB}$ might be different in a real wine matrix.

\section{CONCLUSIONS}

Both CHEF karyotyping and MALDI-TOF MS were effective techniques for identifying wine non-Saccharomyces yeast species and could also be used for the typing of C. zemplinina, H. uvarum, L. thermotolerans and T. delbrueckii strains. Both techniques were unable to adequately type $M$. pulcherrima strains, but CHEF karyotyping showed more potential for the typing of these strains. Yeast enzyme activity appears to be strain dependent, and most of the species investigated did not have extracellular $\beta$-glucosidase, pectinase and protease activity. In the synthetic wine fermentations, the $C$. stellata, C. zemplinina, H. uvarum, M. pulcherrima and Sc. pombe strains were shown to be slow to medium fermenters. The $L$. thermotolerans and T. delbrueckii strains were found to be medium to strong fermenters and comparable to $S$. cerevisiae. Further investigations are needed to evaluate the L. thermotolerans and T. delbrueckii strains as potential single inoculations or co-inoculations with $S$. cerevisiae in grape must, while the $H$. uvarum and M. pulcherrima strains need to be evaluated in co- or sequential inoculations with $S$. cerevisiae. The effect of non-Saccharomyces yeast species on MLF varied and inhibition was found to be strain dependent. All M. pulcherrima and L. thermotolerans strains used in this study were compatible with the $O$. oeni strain and conducive to MLF. In most cases, delays in MLF could be alleviated by nutrient supplementation. Many of the nonSaccharomyces yeast strains evaluated showed potential for use in wine production and warrant further investigation.

\section{LITERATURE CITED}

Alcoba-Flórez, J., Del Pilar Arévalo-Morales, M., Pérez-Roth, E., Laich, F., Rivero-Pérez, B. \& Méndez-Álvarez, S., 2007. Yeast molecular identification and typing. Communicating current research and educational topics and trends in applied microbiology. Formatex Research Center, Extremadura. pp. $535-546$.

Alessandria, V., Marengo, F., Englezos, V., Gerbi, V., Rantsiou, K. \& Cocolin, L., 2015. Mycobiota of Barbera grapes from the piedmont region from a single vintage year. Am. J. Enol. Vitic. 66, 244-250.

Alexandre, H., Costello, P.J., Remize, F., Guzzo, J. \& Guilloux-Benatier, M., 2004. Saccharomyces cerevisiae-Oenococcus oeni interactions in wine: Current knowledge and perspectives. Int. J. Food Microbiol. 93, 141-154.

Baranowski, K. \& Radler, F., 1984. The glucose-dependent transport of L-malate in Zygosaccharomyces bailii. Antonie van Leeuwenhoek 50, 329340 .

Barquet, M., Martín, V., Medina, K., Pérez, G., Carrau, F. \& Gaggero, C., 2012. Tandem repeat-tRNA (TRtRNA) PCR method for the molecular typing of non-Saccharomyces subspecies. Appl. Microbiol. Biotechnol. 93, 807-814.

Bartowsky, E.J., Costello, P.J. \& Chambers, P.J., 2015. Emerging trends in the application of malolactic fermentation. Aust. J. Grape Wine Res. 21(S1), 663-669.

Bartowsky, E.J., Costello, P.J. \& Henschke, P.A., 2002. Management of malolactic fermentation - Wine flavour manipulation. Aust. N.Z. Grapegrow. Winemak. 461, 7-8 and 10-12.

Bauer, R. \& Dicks, L.M.T., 2004. Control of malolactic fermentation in wine. A review. S. Afr. J. Enol. Vitic. 25, 74-88.

Benito, S., Palomero, F., Gálvez, L., Morata, A., Calderón, F., Palmero, D. \& Suárez-Lepe, J.A., 2014. Quality and composition of red wine fermented with Schizosaccharomyces pombe as sole fermentative yeast, and in mixed and sequential fermentations with Saccharomyces cerevisiae. Food Technol. Biotechnol. 52, 376-382.

Benito, S., Palomero, F., Morata, A., Calderón, F. \& Suárez-Lepe, J.A., 2012. New applications for Schizosaccharomyces pombe in the alcoholic fermentation of red wines. Int. J. Food Sci. Technol. 47, 2101-2108.

Benito, S., Palomero, F., Morata, A., Calderón, F., Palmero, D. \& SuárezLepe, J.A., 2013. Physiological features of Schizosaccharomyces pombe of interest in making of white wines. Eur. Food Res. Technol. 236, 29-36.

Bisson, L.F. \& Kunkee, R.E., 1991. Microbial interactions during wine production. In: Zeikus, J.G. \& Johnson, E.A. (eds). Mixed cultures in biotechnology. McGraw-Hill, Inc., New York. pp. $39-68$.

Bokulich, N., Hwang, C.F., Liu, S., Boundy-Mills, K. \& Mills, D., 2012. Profiling the yeast communities of wine fermentation using terminal restriction fragment length polymorphism analysis. Am. J. Enol. Vitic. 63, 185-194. 
Capozzi, V., Garofalo, C., Chiriatti, M.A., Grieco, F. \& Spano, G., 2015. Microbial terroir and food innovation: The case of yeast biodiversity in wine. Microbiol. Res. 181, 75-83.

Charoenchai, C., Fleet, G.H., Henschke, P.A. \& Todd, B.E.N.T., 1997. Screening of non-Saccharomyces wine yeasts for the presence of extracellular hydrolytic enzymes. Aust. J. Grape Wine Res. 3, 2-8.

Ciani, M. \& Maccarelli, F., 1998. Oenological properties of nonSaccharomyces yeasts associated with winemaking. World J. Microb. Biot. 14, 199-203.

Ciani, M. \& Picciotti, G., 1995. The growth kinetics and fermentation behaviour of some non-Saccharomyces yeasts associated with winemaking. Biotechnol. Lett. 17, 1247-1250.

Comitini, F., Ferretti, R., Clementi, F., Mannazzu, I. \& Ciani, M., 2005. Interactions between Saccharomyces cerevisiae and malolactic bacteria: Preliminary characterization of a yeast proteinaceous compound(s) active against Oenococcus oeni. J. Appl. Microbiol. 99, 105-111.

Comitini, F., Gobbi, M., Domizio, P., Romani, C., Lencioni, L., Mannazzu, I. \& Ciani, M., 2011. Selected non-Saccharomyces wine yeasts in controlled multistarter fermentations with Saccharomyces cerevisiae. Food Microbiol. $28,873-882$

Costello, P.J., Henschke, P.A. \& Markides, A.J., 2003. Standardised methodology for testing malolactic bacteria and wine yeast compatibility. Aust. J. Grape Wine Res. 9, 127-137.

Csoma, H. \& Sipiczki, M., 2008. Taxonomic reclassification of Candida stellata strains reveals frequent occurrence of Candida zemplinina in wine fermentation. FEMS Yeast Res. 8, 328-336.

Davis, C.R., Wibowo, D., Eschenbruch, R., Lee, T.H. \& Fleet, G.H., 1985. Practical implications of malolactic fermentation: A review. Am. J. Enol. Vitic. 36, 290-301

Deak, E., Charlton, C.L., Bobenchik, A.M., Miller, S.A., Pollett, S., McHardy, I.H., Wu, M.T. \& Garner, O.B., 2015. Comparison of the Vitek MS and Bruker Microflex LT MALDI-TOF MS platforms for routine identification of commonly isolated bacteria and yeast in the clinical microbiology laboratory. Diagn. Microbiol. Infect. Dis. 81, 27-33.

Di Maio, S., Genna, G., Gandolfo, V., Amore, G., Ciaccio, M. \& Oliva, D., 2012. Presence of Candida zemplinina in Sicilian musts and selection of a strain for wine mixed fermentations. S. Afr. J. Enol. Vitic. 33, 80-87.

Duarte, F.L., Pimentel, N.H., Teixeira, A. \& Fonseca, A., 2012. Saccharomyces bacillaris is not a synonym of Candida stellata: Reinstatement as Starmerella bacillaris comb. nov. Antonie Van Leeuwenhoek 102, 653-658.

Englezos, V., Rantsiou, K., Torchio, F., Rolle, L., Gerbi, V. \& Cocolin, L., 2015. Exploitation of the non-Saccharomyces yeast Starmerella bacillaris (synonym Candida zemplinina) in wine fermentation: Physiological and molecular characterizations. Int. J. Food Microbiol. 199, 33-40.

Esteve-Zarzoso, B., Peris-Torán, M.J., Ramón, D. \& Querol, A., 2001. Molecular characterisation of Hanseniaspora species. Antonie van Leeuwenhoek 80, 85-92.

Fleet, G.H., Prakitchaiwattana, C., Beh, A.L. \& Heard, G., 2002. The yeast ecology of wine grapes. In: Ciani, M. (ed.). Biodiversity and biotechnology of wine yeast. Research Signpost, Kerala, India. pp. $1-17$.

Ganga, M.A. \& Martínez, C., 2004. Effect of wine yeast monoculture practice on the biodiversity of non-Saccharomyces yeasts. J. Appl. Microbiol. 96, 76-83.

Gao, C. \& Fleet, G.H., 1995. Degradation of malic and tartaric acids by high density cell suspensions of wine yeasts. Food Microbiol. 12, 65-71.
Henick-Kling, T. \& Park, Y.H., 1994. Considerations for use of yeast and bacterial starter cultures: $\mathrm{SO}_{2}$ and timing of inoculation. Am. J. Enol. Vitic. 45, 464-469

Hernández-Orte, P., Cersosimo, M., Loscos, N., Cacho, J., Garcia-Moruno, E. \& Ferreira, V., 2008. The development of varietal aroma from non-floral grapes by yeasts of different genera. Food Chem. 107, 1064-1077.

Hoff, J.W., 2012. Molecular typing of wine yeasts: Evaluation of typing techniques and establishment of a database. Thesis, Stellenbosch University, Private Bag X1, 7602 Matieland (Stellenbosch), South Africa.

Iland, P., Ewart, A., Sitters, J., Markides, A. \& Bruer, N., 2000. Techniques for chemical analysis and quality monitoring during winemaking. Patrick Iland Promotions, Campbelltown, Australia.

Jolly, N.P., Augustyn, O.P.H. \& Pretorius, I.S., 2003a. The occurrence of non-Saccharomyces yeast species over three vintages in four vineyards and grape musts from four production regions of the Western Cape, South Africa. S. Afr. J. Enol. Vitic. 24, 35-42.

Jolly, N.P., Augustyn, O.P.H. \& Pretorius, I.S., 2003b. The effect of nonSaccharomyces yeasts on fermentation and wine quality. S. Afr. J. Enol. Vitic. 24, 55-62.

Jolly, N.P., Augustyn, O.P.H. \& Pretorius, I.S., 2003c. The use of Candida pulcherrima in combination with Saccharomyces cerevisiae for the production of Chenin blanc wine. S. Afr. J. Enol. Vitic. 24, 63-69.

Jolly, N.P., Augustyn, O.P.H. \& Pretorius, I.S., 2006. The role and use of non-Saccharomyces yeasts in wine production. S. Afr. J. Enol. Vitic. 27, $15-39$.

Jolly, N.P., Varela, C. \& Pretorius, I.S., 2014. Not your ordinary yeast: NonSaccharomyces yeasts in wine production uncovered. FEMS Yeast Res. 14, 215-237.

Kántor, A. \& Kačániová, M., 2015. Isolation and identification of spoilage yeasts in wine samples by MALDI-TOF MS Biotyper. Scientific Papers: Animal Science and Biotechnologies 48, 156-161.

Lerm, E., Engelbrecht, L. \& Du Toit, M., 2010. Malolactic fermentation: The ABC's of MLF. S. Afr. J. Enol. Vitic. 31, 186-212.

Magyar, I. \& Toth, T., 2011. Comparative evaluation of some oenological properties in wine strains of Candida stellata, Candida zemplinina, Saccharomyces uvarum, and Saccharomyces cerevisiae. Food Microbiol. 28, 94-100.

Magyar, I., Nyitrai-Sárdy, D., Leskó, A., Pomázi, A. \& Kállay, M., 2014. Anaerobic organic acid metabolism of Candida zemplinina in comparison with Saccharomyces wine yeasts. Int. J. Food Microbiol. 178, 1-6.

Marklein, G., Josten, M., Klanke, U., Muller, E., Horre, R., Maier, T., Wenzel, T., Kostrzewa, M., Bierbaum, G., Hoerauf, A. \& Sahl, H.G., 2009. Matrix-assisted laser desorption ionization time of flight mass spectrometry for fast and reliable identification of clinical yeast isolates. J. Clin. Microbiol. 47, 2912-2917.

McKay, A.M., 1988. A plate assay method for the detection of fungal polygalacturonase secretion. FEMS Lett. 56, 355-358.

Minnaar, P.P., Ntushelo, N., Ngqumba, Z., Van Breda, V. \& Jolly, N.P., 2015. Effect of Torulaspora delbrueckii yeast on the anthocyanin and flavanol concentrations of Cabernet franc and Pinotage wines. S. Afr. J. Enol. Vitic. $36,50-58$.

Mocke, B.A., 2005. The breeding of yeast strains for novel oenological outcomes. Thesis, Stellenbosch University, Private Bag X1, 7602 Matieland (Stellenbosch), South Africa.

Moothoo-Padayachie, A., Kandappa, H.R., Krishna, S.B.N., Maier, T. \& Govender, P., 2013. Biotyping Saccharomyces cerevisiae strains using matrix-assisted laser desorption/ionization time-of-flight mass spectrometry (MALDI-TOF MS). Eur. Food Res. Technol. 236, 351-364 
Moreno, J.J., Millán, C., Ortega, J.M. \& Medina, M., 1991. Analytical differentiation of wine fermentations using pure and mixed yeast cultures. J. Ind. Microbiol. 7, 181-190.

Mostert, T.T., 2013. Investigating the secretome of non-Saccharomyces yeast in model wine. Thesis, Stellenbosch University, Private Bag X1, 7602 Matieland (Stellenbosch), South Africa.

Mostert, T.T. \& Divol, B., 2014. Investigating the proteins released by yeasts in synthetic wine fermentations. Int. J. Food Microbiol. 171, 108-118.

Nehme, N., Mathieu, F. \& Taillandier, P., 2008. Quantitative study of interactions between Saccharomyces cerevisiae and Oenococcus oeni strains. J. Ind. Microbiol. Biotechnol. 35, 685-693.

Padilla, B., Gil, J.V. \& Manzanares, P., 2016. Past and future of nonSaccharomyces yeasts: From spoilage microorganisms to biotechnological tools for improving wine aroma complexity. Front. Microbiol. 7, 411. http:// doi.org/10.3389/fmicb.2016.00411

Reid, V.J., 2012. Extracellular acid proteases of wine microorganisms: gene identification, activity characterization and impact on wine. Thesis, Stellenbosch University, Private Bag X1, 7602 Matieland (Stellenbosch), South Africa.

Renault, P., Coulon, J., De Revel, G., Barbe, J.C. \& Bely, M., 2015. Increase of fruity aroma during mixed T. delbrueckii/S. cerevisiae wine fermentation is linked to specific esters enhancement. Int. J. Food Microbiol. 207, 40-48.

Renault, P., Miot-Sertier, C., Marullo, P., Hernández-Orte Lagarrigue, L., Lonvaud-Funel, A. \& Bely, M., 2009. Genetic characterisation and phenotypic variability in Torulaspora delbrueckii species: Potential applications in the wine industry. Int. J. Food Microbiol. 134, 201-210.

Ribéreau-Gayon, P., Dubourdieu, D., Donéche, B. \& Lonvaud, A., 2006 (2 $2^{\text {nd }}$ ed.). Handbook of Enology. The Microbiology of Wine and Vinifications, vol. 1. John Wiley \& Sons Ltd., England.

Rodríguez, M.E., Lopes, C.A., Van Broock, M., Vallés, S., Ramón, D. \& Caballero, A.C., 2004. Screening and typing of Patagonian wine yeasts for glycosidase activities. J. Appl. Microbiol. 96, 84-95.

Rodriquez, S.B. \& Thornton, R.J., 1989. A malic acid dependent mutant of Schizosaccharomyces malidevorans. Arch. Microbiol. 152, 564-566.

Rojas, V., Gil, J.V., Piñaga, F. \& Manzanares, P., 2003. Acetate ester formation in wine by mixed cultures in laboratory fermentations. Int. J. Food Microbiol. 86, 181-188.

Romano, P., Capece, A. \& Jespersen, L., 2006. Taxonomic and ecological diversity of food and beverage yeasts. In: Querol, A. \& Fleet, G.H. (eds). The yeast handbook - Yeasts in food and beverages. Springer-Verlag, Berlin \& Heidelberg. pp. $13-53$.

Romano, P., Fiore, C., Paraggio, M., Caruso, M. \& Capece, A., 2003. Function of yeast species and strains in wine flavour. Int. J. Food Microbiol. 86(1), 169-180.

Romano, P., Suzzi, G., Domizio, P. \& Fatichenti, F., 1997. Secondary products formation as a tool for discriminating non-Saccharomyces wine strains. Antonie van Leeuwenhoek 71, 239-242.

Rosi, I., Vinella, M. \& Domizio, P., 1994. Characterization of $\beta$-glucosidase activity in yeasts of oenological origin. J. Appl. Bacteriol. 77, 519-527.
Saayman, M. \& Viljoen-Bloom, M., 2006. The biochemistry of malic acid metabolism by wine yeasts - A review. S. Afr. J. Enol. Vitic. 27, 113-122.

Scholtz, M., 2013. Assessing the compatibility and aroma production of NT 202 co-inoculant with different wine yeasts and additives. Thesis, Stellenbosch University, Private Bag X1, 7602 Matieland (Stellenbosch), South Africa.

Sipiczki, M., 2003. Candida zemplinina sp. nov., an osmotolerant and psychrotolerant yeast that ferments sweet botrytized wines. Int. J. Syst. Evol. Microbiol. 53, 2079-2083.

Sipiczki, M., 2004. Species identification and comparative molecular and physiological analysis of Candida zemplinina and Candida stellata. J. Basic Microbiol. 44, 471-479.

Spadaro, D., Sabetta, W., Acquadro, A., Portis, E., Garibaldi, A. \& Gullino, M.L., 2008. Use of AFLP for differentiation of Metschnikowia pulcherrima strains for postharvest disease biological control. Microbiol. Res. 163, 523530 .

Strauss, M.L.A., 2003. The transformation of wine yeasts with glucanase, xylanase and pectinase genes for improved clarification and filterability of wine. Thesis, Stellenbosch University, Private Bag X1, 7602 Matieland (Stellenbosch), South Africa.

Strauss, M.L., Jolly, N.P., Lambrechts, M.G. \& Van Rensburg, P., 2001. Screening for the production of extracellular hydrolytic enzymes by nonSaccharomyces wine yeasts. J. Appl. Microbiol. 91, 182-190.

Sumby, K.M., Grbin, P.R. \& Jiranek, V., 2014. Implications of new research and technologies for malolactic fermentation in wine. Appl. Microbiol Biotechnol. 98, 8111-8132.

Van Breda, V., 2012. The use of Torulaspora delbrueckii for wine production. Thesis. Cape Peninsula University of Technology, Cape Town 8000 , South Africa

Van Breda, V., Jolly, N. \& Van Wyk, J., 2013. Characterisation of commercial and natural Torulaspora delbrueckii wine yeast strains. Int. J. Food Microbiol. 163, 80-88.

Van Rensburg, P. \& Pretorius, I.S., 2000. Enzymes in winemaking: Harnessing natural catalysts for efficient biotransformations - A review. S. Afr. J. Enol. Vitic. 21(Special issue), 52-73.

Van Veen, S.Q., Claas, E.C. \& Kuijper, E.J., 2010. High-throughput identification of bacteria and yeast by matrix-assisted laser desorption ionization-time of flight mass spectrometry in conventional medical microbiology laboratories. J. Clin. Microbiol. 48, 900-907.

Visintin, S., Alessandria, V., Valente, A., Dolci, P. \& Cocolin, L., 2016. Molecular identification and physiological characterization of yeasts, lactic acid bacteria and acetic acid bacteria isolated from heap and box cocoa bean fermentations in West Africa. Int. J. Food Microbiol. 216, 69-78.

Volschenk, H., Van Vuuren, H.J.J. \& Viljoen-Bloom, M., 2003. Maloethanolic fermentation in Saccharomyces and Schizosaccharomyces. Curr. Genet. 43, 379-391.

Wibowo, D., Eschenbruch, R., Davis, C.R., Fleet, G.H. \& Lee, T.H., 1985. Occurrence and growth of lactic acid bacteria in wine: A review. Am. J. Enol. Vitic. 36, 302-313. 